\title{
Monoacylglycerol Lipase Inhibitors Reverse Paclitaxel-Induced Nociceptive Behavior and Proinflammatory Markers in a Mouse Model of Chemotherapy-Induced Neuropathy ${ }^{\text {[ }}$
}

\author{
Zachary A. Curry, Jenny L. Wilkerson, Deniz Bagdas, S. Lauren Kyte, Nipa Patel, \\ Giulia Donvito, Mohammed A. Mustafa, Justin L. Poklis, Micah J. Niphakis, Ku-Lung Hsu, \\ Benjamin F. Cravatt, David A. Gewirtz, M. Imad Damaj, and Aron H. Lichtman \\ Department of Pharmacology and Toxicology, Virginia Commonwealth University, Richmond, Virginia (Z.A.C., J.L.W., D.B., S.L. \\ K., N.P., G.D., M.A.M., J.L.P., D.A.G., M.I.D., A.H.L.); The Skaggs Institute for Chemical Biology and Department of Chemical \\ Physiology, The Scripps Research Institute, La Jolla, California (M.J.N., B.F.C.); and Department of Chemistry, University of \\ Virginia, Charlottesville, Virginia (K.-L.H.)
}

Received October 14, 2017; accepted March 8, 2018

\section{ABSTRACT}

Although paclitaxel effectively treats various cancers, its debilitating peripheral neuropathic pain side effects often persist long after treatment has ended. Therefore, a compelling need exists for the identification of novel pharmacologic strategies to mitigate this condition. As inhibitors of monoacylglycerol lipase (MAGL), the primary hydrolytic enzyme of the endogenous cannabinoid, 2-arachidonyolglycerol, produces antinociceptive effects in numerous rodent models of pain, we investigated whether inhibitors of this enzyme (i.e., JZL184 and MJN110) would reverse paclitaxel-induced mechanical allodynia in mice. These drugs dose dependently reversed allodynia with respective $\mathrm{ED}_{50}$ values (95\% confidence limit) of 8.4 (5.2-13.6) and 1.8 (1.0-3.3) $\mathrm{mg} / \mathrm{kg}$. Complementary genetic and pharmacologic approaches revealed that the antiallodynic effects of each drug require both cannabinoid receptors, $\mathrm{CB}_{1}$ and $\mathrm{CB}_{2}$. MJN110 reduced paclitaxel-mediated increased expression of monocyte chemoattractant protein-1 (MCP-1, CCL2) and phospho-p38 MAPK in dorsal root ganglia as well as MCP-1 in spinal dorsal horn. Whereas the antinociceptive effects of high dose JZL184 $(40 \mathrm{mg} / \mathrm{kg}$ ) underwent tolerance following 6 days of repeated dosing, repeated administration of a threshold dose (i.e., $4 \mathrm{mg} / \mathrm{kg}$ ) completely reversed paclitaxel-induced allodynia. In addition, we found that the administration of MJN110 to control mice lacked intrinsic rewarding effects in the conditioned place preference (CPP) paradigm. However, it produced a CPP in paclitaxel-treated animals, suggesting a reduced paclitaxelinduced aversive state. Importantly, JZL184 did not alter the antiproliferative and apoptotic effects of paclitaxel in A549 and H460 non-small cell lung cancer cells. Taken together, these data indicate that MAGL inhibitors reverse paclitaxel-induced neuropathic pain without interfering with chemotherapeutic efficacy.

\section{Introduction}

Paclitaxel is a widely prescribed chemotherapeutic for the treatment of breast, lung, and other cancers, but causes a

This research was supported by National Institutes of Health National Institute on Drug Abuse [Grants DA007027, DA033760, DA033934, DA035864, DA038493], National Cancer Institute [Grants CA206028, CA016059], and National Institute of Neurological Disorders and Stroke [Grant NS093990]. Funding was also provided by a Massey Cancer Center Pilot Project Grant to D.A.G. and M.I.D., as well as start-up funds from the VCU School of Pharmacy to A.H.L. Services in support of the research project were provided by the VCU Massey Cancer Center Cancer Mouse Model Shared Resource, the VCU Massey Cancer Center Flow Cytometry Shared Resource and the VCU Microscopy Facility, supported, in part, with funding from NIH-NCI Cancer Center Support Grant P30 CA016059. Dr. Bagdas' effort was supported in part by P50DA036105 and the Center for Tobacco Products of the U.S. Food and Drug Administration.

https://doi.org/10.1124/jpet.117.245704.

S This article has supplemental material available at jpet.aspetjournals.org. variety of serious side effects, including peripheral neuropathy, leukopenia, joint or muscle pain, vomiting, and alopecia (Ghersi et al., 2015). Chemotherapy-induced peripheral neuropathy (CIPN) causes severe sensory disturbances that range from mild tingling to spontaneous painful burning paresthesia affecting the longest sensory nerves to the hands and feet (Dougherty et al., 2004) and can persist long after treatment cessation (Tanabe et al., 2013) in up to $68 \%$ of chemotherapy cancer patients (Seretny et al., 2014). As traditional analgesics generally lack efficacy in treating this condition (Kim et al., 2015), a pressing need exists for novel analgesic strategies. However, the endogenous cannabinoid system contains several potential targets of promise to treat CIPN. Here, we employ a mouse paclitaxel model of CIPN to explore whether inhibition of monoacylglycerol lipase (MAGL) (Dinh et al., 2002), the primary hydrolytic enzyme of the endogenous cannabinoid 2-arachidonoylglycerol (2-AG) (Mechoulam et al.,

ABBREVIATIONS: ABHD6, alpha beta hydrolase domain-containing protein 6; AEA, anandamide; 2-AG, 2-arachidonoylglycerol; ANOVA, analysis of variance; CIPN, chemotherapy-induced peripheral neuropathy; CPP, conditioned place preference; DMEM, Dulbecco's modified Eagle's medium; DRG, dorsal root ganglia; MAGL, monoacylglycerol lipase; MCP-1, monocyte chemoattractant protein-1; NSCLC, non-small cell lung cancer; PBS, phosphate-buffered saline; $\mathrm{PGD}_{2}$, prostaglandin $\mathrm{D} 2$. 
1995; Sugiura et al., 1995; Blankman et al., 2007), will reduce nociceptive behavior and associated inflammatory responses.

MAGL inhibitors increase 2-AG, decrease arachidonic acid levels in the central nervous system (Long et al., 2009), and produce antiallodynic effects in rodent neuropathic pain models, including chronic constriction injury of the sciatic nerve (Ignatowska-Jankowska et al., 2015; Wilkerson et al., 2016b; Crowe et al., 2017) and cisplatin neuropathy (Guindon et al., 2013). Importantly, the $\mathrm{CB}_{2}$ receptor agonist AM1710 (Deng et al., 2015b) and the MAGL inhibitor JZL184 (Slivicki et al., 2017) reverse paclitaxel-induced allodynia in mice. In the present study, we build upon this work using the MAGL inhibitors JZL184 (Long et al., 2009) and MJN110 (Niphakis et al., 2013) in the paclitaxel mouse model of CIPN. Although MJN110 is more potent than JZL184 (Ignatowska-Jankowska et al., 2015), it also inhibits $\alpha / \beta$-hydrolase domain 6 (ABHD6) (Niphakis et al., 2013), which metabolizes a much smaller percentage of 2-AG than MAGL (Blankman et al., 2007). To control for this off-target effect, we tested the selective ABHD6 inhibitor [4-(4'-methoxy[1,1' -biphenyl]-4-yl)-1H-1,2,3-triazol1-yl](2-phenyl-1-piperidinyl)-methanone (KT195) (Hsu et al., 2012; Wilkerson et al., 2016a). We used complementary genetic and pharmacologic approaches to assess the contribution of $\mathrm{CB}_{1}$ and $\mathrm{CB}_{2}$ receptors to observed pharmacological effects of the inhibitors. Because CIPN persists in patients long after chemotherapy treatment, we explored whether the antinociceptive effects of JZL184 would undergo tolerance or be maintained after repeated administration. We also explore whether repeated administration of JZL184 increases endocannabinoid levels and decreases arachidonic acid levels, along with prostaglandin D2 ( $\mathrm{PGD}_{2}$ ) (Nomura et al., 2011b), in the lumbar spinal cord of paclitaxel-treated mice.

In addition to neurotoxicity (Bobylev et al., 2015), paclitaxel causes inflammation within the dorsal root ganglia (DRG) and activates toll-like receptor 4 (Li et al., 2014) with subsequent p38 MAPK expression and activation through phosphorylation, increasing phosphorylated p38 MAPK (phospho-p38) (Li et al., 2015). Paclitaxel also increases the chemokine monocyte chemoattractant protein-1 (MCP-1)/(C-C motif) ligand 2 (CCL2) expression in the DRG (Zhang et al., 2013; Makker et al., 2017) and the spinal cord (Pevida et al., 2013; Zhang et al., 2013), causing sensory neuron sensitization through transient receptor potential channel activation (Jung et al., 2008) and increased intracellular calcium (Zhang et al., 2013). Inhibition of MCP-1 signaling reverses and prevents paclitaxel-induced allodynia (Zhang et al., 2013). In contrast, inhibition of phospho-p38 does not reverse but prevents (Li et al., 2015) paclitaxel-induced allodynia. Although a $\mathrm{CB}_{2}$ receptor agonist inhibits spinal MCP-1 expression associated with paclitaxel (Deng et al., 2015b), MAGL inhibitors remain unexplored. Accordingly, we tested whether MAGL inhibition would ameliorate paclitaxel-induced expression of MCP-1 and phospho-p38 in the DRG and spinal dorsal horn.

Along with mechanical allodynia, we assessed whether MJN110 produces a conditioned place preference (CPP) in paclitaxel-treated mice. The CPP paradigm allows for disassociation of a drug's analgesic profile and its intrinsic rewarding effects, as shown for cisplatin neuropathy (Park et al., 2013; Krukowski et al., 2017) and osteoarthritis (Havelin et al., 2016). However, CPP has not been used in paclitaxelinduced CIPN to examine MAGL inhibitors. Here, we test whether MJN110 produces a CPP in paclitaxel-treated mice, indicating relief from an aversive state not observed in control mice.

Finally, as paclitaxel-induced CIPN develops during chemotherapy treatment, it is important to test whether candidate antinociceptive agents, such as MAGL inhibitors, interfere with paclitaxel's antitumor effects. Thus we examined whether JZL184 affects the antiproliferative and apoptotic activity of paclitaxel in the human cell lines of non-small cell lung cancer (NSCLC) (Johnson et al., 2006) A549 (Marostica et al., 2015) and H460 (Huisman et al., 2002) cells.

\section{Materials and Methods}

Animals. Adult male C57BL/6J mice with starting weights of $24.8 \pm 0.16 \mathrm{~g}$ (Jackson Laboratories, Bar Harbor, ME) were used in all studies except in experiments employing $\mathrm{CB}_{1}(-/-)$ and $\mathrm{CB}_{2}(-/-)$ mice. Male and female $\mathrm{CB}_{1}(-/-)$ (Zimmer et al., 1999) and $\mathrm{CB}_{2}(-/-)$ (Jackson Laboratories) and matched wild-type control mice were received from the Virginia Commonwealth University (VCU) Massey Cancer Center Transgenic/Knockout Mouse Shared Resource. Both lines of transgenic mice have been backcrossed with C57BL/6J mice. Based on genotyping analysis, $\mathrm{CB}_{1}(-/-)$ mice were $90 \%$ similar to C57BL/6J, 6\% similar to C57BL/6N, and $4 \%$ similar to $129 / \mathrm{Sv}$ mice. $\mathrm{CB}_{2}(-/-)$ mice were $71 \%$ similar to $\mathrm{C} 57 \mathrm{BL} / 6 \mathrm{~J}$ and $27 \%$ similar to $\mathrm{C} 57 \mathrm{BL} / 6 \mathrm{~N}$ and $2 \%$ similar to $129 / \mathrm{Sv}$ mice. Animals were housed four per cage, with separation as needed when fighting, and maintained in the AAALAC-approved vivarium at Virginia Commonwealth University. Animals were provided with water and Teklad LM-485 Mouse Diet (7012; Envigo/Teklad Diets, Madison, WI) chow ad libitum with a 12-hour light/dark cycle beginning at 0600. Animal studies were conducted in compliance with the National Institutes of Health Guide for the Care and Use of Laboratory Animals and approved by the VCU Institutional Animal Care and Use Committee. Before the studies were started employing the transgenic mice, the VCU vivarium was undergoing renovation. Thus, these mice were moved between vivarium rooms and exposed to construction noise. For all other studies, mice were housed undisturbed in the vivarium. Following behavioral testing, animals were euthanized using $\mathrm{CO}_{2}$ asphyxiation and cervical dislocation unless tissue collection was performed. Tissue collection was performed after either rapid decapitation or isoflurane anesthesia.

Assessment of Mechanical Allodynia. Mice received a minimum of 4 days prior to experimentation to acclimate to the vivarium. Prior to behavioral assessment, mice were acclimated to the von Frey mesh elevated platform for a minimum of $40 \mathrm{~min} /$ day for a minimum of 3 days. During acclimation and testing, each mouse was placed in a ventilated Plexiglas cylinder, approximately 3 inches in diameter, minimizing locomotor activity. To assess paw withdrawal thresholds, von Frey filaments (North Coast Medical, Gilroy, CA) were applied to the hind paw for 3 seconds on each of three trials until a positive response was noted as a paw withdrawal to the stimulus. Testing began at the $0.6 \mathrm{~g}$ filament and moved sequentially to higher values $(1,1.4,2,4 \mathrm{~g})$ until five of six withdrawals were recorded. If a response occurred at $0.6 \mathrm{~g}$, the $0.4,0.16$, and $0.07 \mathrm{~g}$ filaments were sequentially applied until five of six positive responses were obtained. A sixth test was not conducted if the first five tests were positive. A maximum of $4 \mathrm{~g}$ was used to prevent sensitization. Results for each animal are reported as the average of both hind paws.

Drugs and Dosing. Paclitaxel (Taxol; Tocris Bioscience, Bristol, UK) was dissolved in a vehicle solution containing a 1:1:18 ratio of ethanol, emulphor-620 (Rhodia, Cranbury, NJ), and saline $(0.9 \%$ $\mathrm{NaCl})$. A cycle of paclitaxel consisted of a total of four intraperitoneal injections of paclitaxel ( $8 \mathrm{mg} / \mathrm{kg}$ per injection) in which injections were given every other day (Toma et al., 2017). Control (no paclitaxel) mice were given four injections of vehicle. The injection volumes were $0.01 \mathrm{ml} / \mathrm{g}$ of body mass. The Cravatt Laboratory at Scripps Research 
Institute, La Jolla, CA, synthesized MJN110 and KT195, and the Drug Supply Program at the National Institute on Drug Abuse (Bethesda, MD) provided JZL184, rimonabant, and SR1445528. Doses of JZL184 (Long et al., 2009; Ghosh et al., 2013; Ignatowska-Jankowska et al., 2015), MJN110 (Niphakis et al., 2013; Ignatowska-Jankowska et al., 2015; Wilkerson et al., 2016b), and KT-195 (Hsu et al., 2012; Wilkerson et al., 2016a) were selected based on the results of previous in vivo and in vitro studies using these agents.

Following basal paw withdrawal assessment, paclitaxel or corresponding vehicle was administered as described above. Paclitaxeltreated and vehicle-pretreated control mice were separately housed to prevent cross-contamination. After confirmation of paw withdrawal thresholds, drugs were administered intraperitoneally and mice were placed on the mesh for a minimum of 30 minutes prior to drug testing. Testing was conducted in a blinded manner with respect to acute drug treatment, and a 72-hour washout period was imposed between drug treatments as previously described (Ignatowska-Jankowska et al., 2015; Wilkerson et al., 2016a). All experiments were completed within 8 weeks of the last paclitaxel/vehicle injection with a minimum 5-day washout period before switching drugs. The same cohorts of $\mathrm{CB}_{1}(-/-)$ and $\mathrm{CB}_{2}(-/-)$ and $(+/+)$ mice were used to test MJN110 and JZL184 within 5 weeks following paclitaxel cessation. A 1-week washout period was used before switching drugs in these animals. For time course studies, testing began 0.5 hours after drug administration and was finished 24 hour posttreatment. Unless otherwise indicated, the antinociceptive effects of MJN110 were tested 3 hours postadministration, while those of JZL184 was tested 2 hours posttreatment. Rimonabant or SR144528 was administered 30 minutes prior to JZL184 or MJN110 (Wilkerson et al., 2016b). Allodynia was confirmed prior to each test and persisted at 8 weeks postpaclitaxel when testing was completed.

In the repeated JZL184 dosing experiment, C57BL/6J mice received a cycle of paclitaxel or vehicle and 10-12 days later received repeated intraperitoneal injections of JZL184 or vehicle as previously described (Kinsey et al., 2013). Mice in the repeated JZL184 conditions received a daily intraperitoneal injection of JZL184 (4 or $40 \mathrm{mg} / \mathrm{kg}$ ) for 6 days. For the acute conditions, each mouse was given a daily intraperitoneal injection of vehicle for 5 days and administered vehicle or JZL184 (4 or $40 \mathrm{mg} / \mathrm{kg}$ ) on day 6 . All mice were tested for mechanical allodynia 2 hours following the final injection on day 6 .

Immunohistochemistry. Immunohistochemistry was conducted as previously described (Wilkerson et al., 2012, 2016a) with slight modifications. Briefly, 9 days after the cycle of paclitaxel or vehicle, mice were given an intraperitoneal injection of MJN110 $(5 \mathrm{mg} / \mathrm{kg})$ or vehicle, and 3 hours later the mice were deeply anesthetized with isoflurane and perfused transcardially with saline followed by $4 \%$ paraformaldehyde in $0.1 \mathrm{M}$ phosphate-buffered saline (PBS), pH 7.4 (Thermo Fisher Scientific, Waltham, MA). Whole spinal columns were collected and fixed overnight in $4 \%$ paraformaldehyde at $4^{\circ} \mathrm{C}$. Spinal columns then underwent EDTA decalcification (8\% in PBS) for approximately 60 days and were sliced in $7-\mu \mathrm{m}$-thick sections. DRG sections corresponding to the L5-L6 spinal cord were selectively examined. Tissue processing, paraffin embedding, and slide preparation was provided by the Virginia Commonwealth University Cancer Mouse Models Core.

Samples were deparaffinized in Hemo De (Electron Microscopy Sciences, Hatfield, PA) and rehydrated in $100 \%$ and $70 \%(\mathrm{v} / \mathrm{v})$ ethanol (Pharmco-AAPER, Brookfield, CT) followed by PBS (Abcam, Cambridge, MA). Antigen retrieval was conducted in a pressure cooker (10 PSI) for 10 minutes in citrate buffer $(2.1 \mathrm{~g} / 100 \mathrm{ml}$ deionized water, $\mathrm{pH}$ 6) followed by 10 minutes of cooling and 5 minutes in room temperature PBS. Slides were blocked for 5 to 6 hours in $4.6 \%$ normal donkey serum/PBS solution. Primary antibodies were applied in $0.5 \%$ bovine serum albumin/PBS solution with $1 \%$ sodium azide and incubated overnight at $4^{\circ} \mathrm{C}$. The following primary antibodies were used: rat anti-MCP-1 (1:50, ab8101; Abcam) (Zoja et al., 1997; Park et al., 2011) and rabbit anti-phospho-p38 MAPK (1:800, 4511S; Cell Signaling, Danvers, MA) (Wilkerson et al., 2012; Shi et al., 2017). On the following day, slides were incubated in secondary antibodies at room temperature. For MCP-1, rhodamine red donkey anti-rat (1:2000, 712-295-153; Jackson ImmunoResearch Laboratories, West Grove, PA) was used for 2 hours. For phospho-p38 MAPK, samples were incubated in biotinylated donkey anti-rabbit (1:1000 for DRG,1: 1300 for dorsal horn; 711-065-152; Jackson ImmunoResearch Laboratories) for 1 hour, followed by processing with the Ultra-Sensitive ABC Peroxidase Standard Staining Kit (32050; Thermo Fisher Scientific) and TSA Plus Cyanine 3 and Fluorescein System (PerkinElmer, Waltham, MA). Slides were then incubated in PBS, followed by a dip in deionized water and placed under a cover slip using Vectashield Antifade Mounting Medium with DAPI (H-1200; Vector Laboratories, Burlingame, CA). Imaging was done at $40 \times$ with a Zeiss AxioObserver A1 inverted microscope equipped with an Axiocam MRc5 color CCD camera and ZEN 2012 software (Carl Zeiss AG, Thornwood, NY) at the Virginia Commonwealth University Microscopy Facility. Images were converted to grayscale and underwent rethresholding to reduce background fluorescence using Zeiss ZEN lite software (Carl Zeiss AG) in a manner that was consistent across all treatment groups for each study. Spinal cord images were rotated or inverted as necessary for consistent orientation.

Densitometry analysis was conducted as previously described (Wilkerson et al., 2012, 2016a; Bagdas et al., 2016) according to the methods of Samudio-Ruiz et al. (2009), Zhang et al. (2012). Densitometry analysis was conducted using Image $J$ by selecting the anatomic location of the DRG or spinal dorsal horn in each image in an unbiased manner. For phospho-p38 MAPK analysis, four stained nuclei were selected at random from each image. Results are reported as the average of four separate sections per animal minus the average of four sections from a control slide lacking primary antibody. A sample size of four animals for each treatment condition was used.

For confocal microscopy and colocalization analysis, images were acquired at $63 \times$ using a Zeiss AxioObserver inverted LSM710 META confocal microscope and ZEN 2012. The entire z-stack of a region was collected, and final images were generated from a single image along the z-plane.

Lipid Quantification. Quantification of endogenous cannabinoids was conducted as previously described (Ramesh et al., 2011; Ignatowska-Jankowska et al., 2015). Briefly, mice in the repeated administration study underwent mechanical allodynia testing and were euthanized by decapitation approximately $3-6$ s hour after drug administration, a time point known to produce reliable elevations in 2-AG and decreased arachidonic acid (Long et al., 2009). Spinal cord tissues were rapidly collected by hydraulic extrusion flushing the spinal canal with saline. The spinal cord was dissected to isolate the lumbar enlargement region (L4-L6), which was immediately frozen and stored at $-80^{\circ} \mathrm{C}$ until further processing.

On the day of lipid extraction, the pre-weighed mouse samples were homogenized with $1.4 \mathrm{ml}$ chloroform:methanol (containing $0.0348 \mathrm{~g}$ PMSF/ml), as previously described (Kinsey et al., 2013). Six-point calibration curves ranged from 0.078 to $10 \mathrm{pmol}$ for AEA, 0.125 to $16 \mathrm{nmol}$ for 2-AG, arachidonic acid and 1.75 to 140 pmol $\mathrm{PGD}_{2}$, a negative control, and blank control were prepared. Internal standards (50 $\mu \mathrm{l}$ of each of $1 \mathrm{pmol}$ AEA- $\mathrm{d}_{8}, 1 \mathrm{nmol} 2-\mathrm{AG}-\mathrm{d}_{8}, 1 \mathrm{nmol}$ arachidonic acid- $\mathrm{d}_{8}$ and 14 pmol $\mathrm{PGD}_{2}-\mathrm{d}_{4}$ ) were added to each calibrator, control and sample, except the blank control. Each calibrator, control, and sample was then mixed with $0.3 \mathrm{ml}$ of $0.73 \% \mathrm{w} / \mathrm{v} \mathrm{NaCl}$, vortexed, and centrifuged ( 10 minutes at $4000 \mathrm{~g}$ and $4^{\circ} \mathrm{C}$ ). The aqueous phase plus debris were collected and extracted again twice with $0.8 \mathrm{ml}$ chloroform, the organic phases were pooled and organic solvents were evaporated under nitrogen gas. Dried samples were reconstituted with $0.1 \mathrm{ml}$ chloroform, mixed with $1 \mathrm{ml}$ cold acetone, and centrifuged (10 minutes at $4000 \mathrm{~g}$ and $4^{\circ} \mathrm{C}$ ) to precipitate proteins. The upper layer was collected and evaporated to dryness and reconstituted with $0.1 \mathrm{ml}$ methanol and placed in auto-sample vials for analysis.

The ultraperformance liquid chromatography-tandem mass spectrometer analysis of AEA, 2-AG, arachidonic acid and $\mathrm{PGD}_{2}$ was performed on a Sciex 6500 QTRAP system with an IonDrive Turbo 


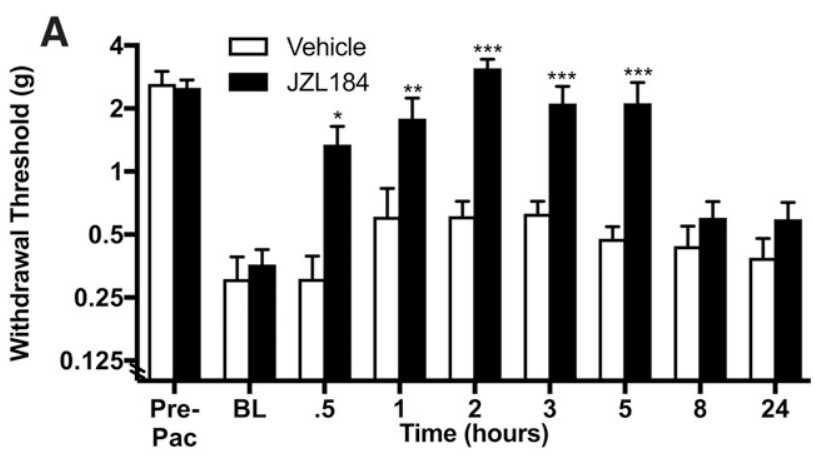

B

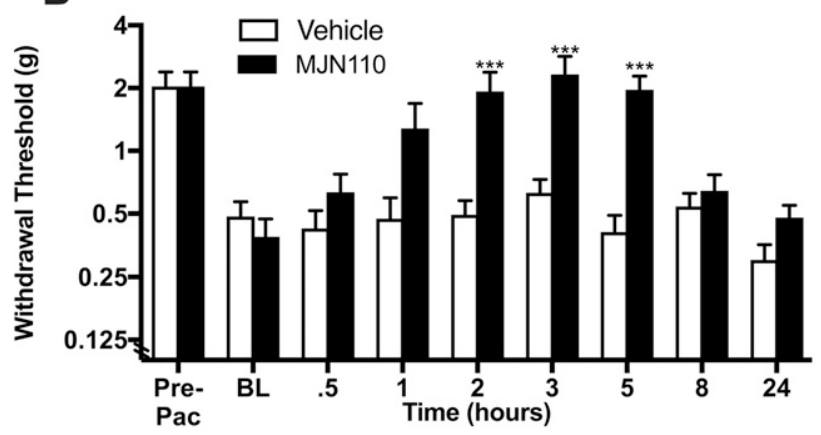

C

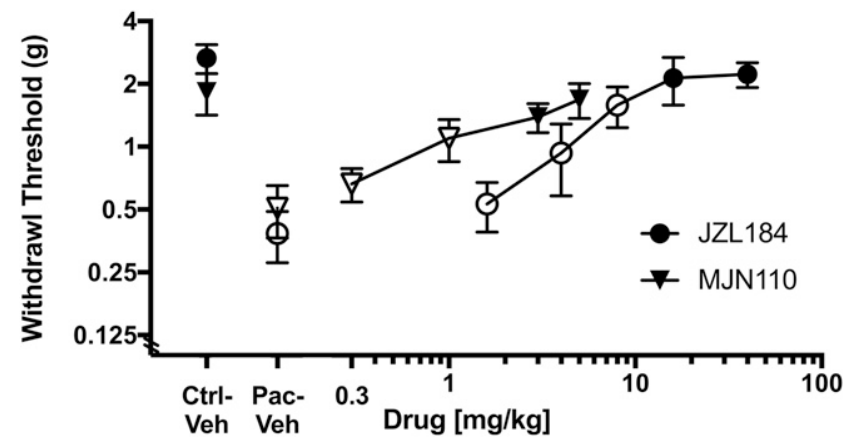

Fig. 1. MAGL inhibitors significantly reverse mechanical allodynia in paclitaxel-treated mice. (A) JZL184 $(40 \mathrm{mg} / \mathrm{kg}$ ) reverses paclitaxel-induced allodynia with maximal antiallodynic effectU+0073 occurring from 0.5 to 5 hours postadministration compared with baseline (BL). (B) MJN110 reverses mechanical allodynia with maximal effects occurring 2-5 hours postinjection. Pre-Pac $=$ baseline prior to paclitaxel $(\mathrm{Pac})$ treatment. $(\mathrm{C})$ JZL184 and MJN110 dose-dependently reverse mechanical allodynia in separate cohorts of paclitaxel-treated mice. Maximum reversal of allodynia was comparable to vehicle control mice treated with vehicle (Ctrl-Veh) for both drugs, as they did not significantly differ. Data are reported as mean \pm S.E.M., $n=7$ or 8 mice/group. ${ }^{*} P<0.05 ; * * P<0.01$; $* * * P<0.001$ vs. vehicle-treated mice at the respective time point (A and B). Filled symbols indicate a significant effect $(P<0.05)$ of drug vs. vehicle-treated mice that received a cycle of paclitaxel (C).

V source for TurbolonSpray (ON, Canada) attached to a Shimadzu UPLC system (Kyoto, Japan) controlled by Analyst software (ON, Canada). Chromatographic separation of AEA, 2-AG, and arachidonic acid was performed on a Discovery HS C18 column $15 \mathrm{~cm} \times 2.1 \mathrm{~mm}$, $3 \mu \mathrm{m}$ (Supelco, Bellefonte, $\mathrm{PA}$ ) kept at $25^{\circ} \mathrm{C}$ and an injection volume of $10 \mu \mathrm{l}$. The mobile phase consisted of A: acetonitrile and B: water with $1 \mathrm{~g} / \mathrm{l}$ ammonium acetate and $0.1 \%$ formic acid. The following gradient was used: $0.0-2.4$ minutes at $40 \% \mathrm{~A}, 2.5-6.0$ minutes at $40 \% \mathrm{~A}$, hold for 2.1 minutes at $40 \% \mathrm{~A}$, then $8.1-9$ minutes $100 \% \mathrm{~A}$, hold at $100 \% \mathrm{~A}$ for 3.1 minutes, and return to $40 \% \mathrm{~A}$ at 12.1 minutes with a flow rate was $1.0 \mathrm{ml} / \mathrm{min}$. The source temperature was set at $600^{\circ} \mathrm{C}$ and had a curtain gas at a flow rate of $30 \mathrm{ml} / \mathrm{min}$. The ionspray voltage was
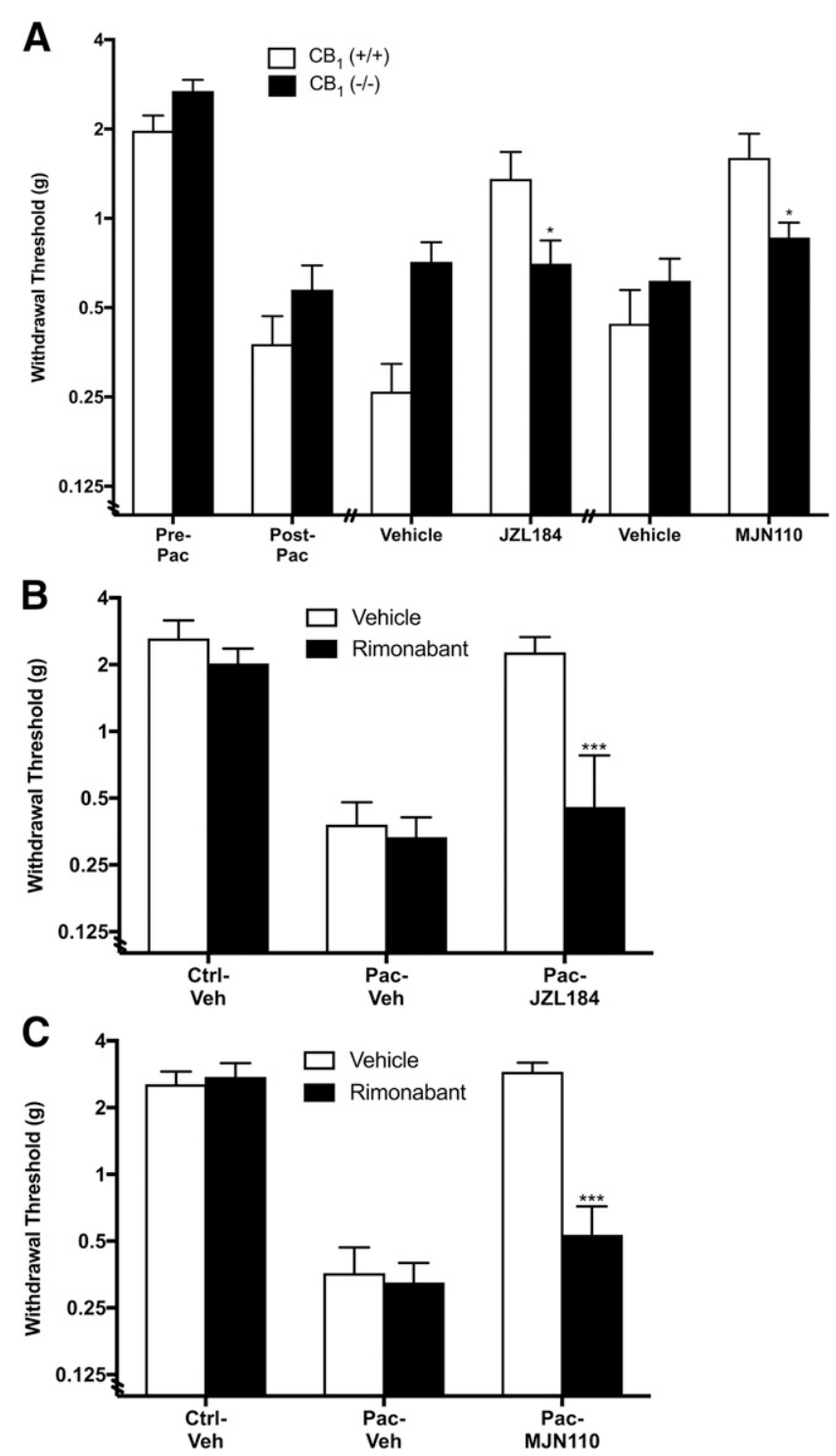

Fig. 2. Antiallodynic effects of MAGL inhibitors require $\mathrm{CB}_{1}$ receptor activation. (A) A cycle of paclitaxel (Pac) leads to the development of mechanical allodynia in $\mathrm{CB}_{1}(+/+)$ and $(-/-)$ mice. JZL184 and MJN110 significantly reverse mechanical allodynia in $\mathrm{CB}_{1}(+/+)$ mice, but not in $\mathrm{CB}_{1}(-/-)$ mice. The $\mathrm{CB}_{1}$ receptor antagonist rimonabant significantly blocks the antiallodynic effects of JZL184 (B) and MJN110 (C). Control (Ctrl) mice and vehicle (Veh) treatment groups are shown for comparison. Data are reported as mean \pm S.E.M., $n=7$ or 8 mice/group. ${ }^{*} P<0.05$ vs. $\mathrm{CB}_{1}(+/+)$ mice (A). ${ }^{* * * P}<0.001$ vs. vehicle pre-treatment (B and $\mathrm{C}$ ).

$5000 \mathrm{~V}$ with ion source gases 1 and 2 flow rates of 60 and $50 \mathrm{ml} / \mathrm{min}$, respectively. The mass spectrometer was run in positive ionization mode for AEA and 2-AG and in negative ionization mode for arachidonic acid, and the acquisition mode used was multiple reaction monitoring. The following transition ions $(\mathrm{m} / z)$ were monitored with their corresponding collection energies (eV) in parentheses: AEA: $348>62$ (13) and $348>$ 91 (60); AEA-d 8 : $356>63$ (13); 2-AG: $379>287$ (26) and $379>296$ (28); 2-AG-d 8 : $384>287$ (26); arachidonic acid: $303>259(-25)$ and $303>$ 59 (-60); arachidonic acid-d 8 : $311>267(-25)$; PGD $_{2}: 351>271(-23)$ and $351>315(-15) ; \mathrm{PGD}_{2}-\mathrm{d}_{4}: 355>275(-23)$. The total run time for the analytical method was 14 minute. Calibration curves were analyzed with each analytical batch for each analyte. A linear regression of the ratio of the peak area counts of analyte and the corresponding deuterated internal standards versus concentration was used to construct the calibration curves. 

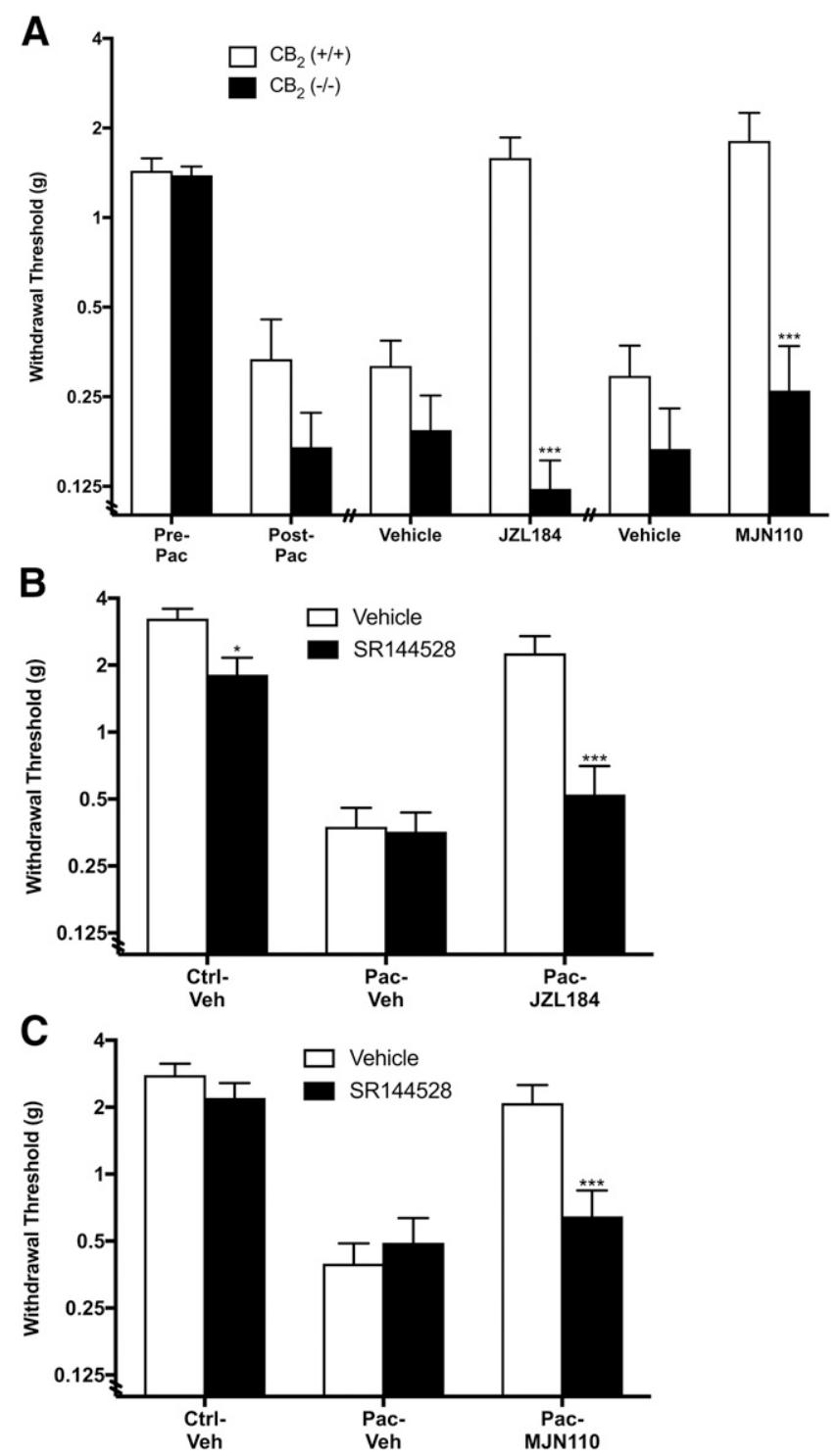

Fig. 3. Antiallodynic effects of MAGL inhibitors require $\mathrm{CB}_{2}$ receptor activation. (A) A cycle of paclitaxel (Pac) leads to the development of mechanical allodynia in $\mathrm{CB}_{2}(+/+)$ and $(-/-)$ mice. JZL184 and MJN110 lack antiallodynic effects in $\mathrm{CB}_{2}(-/-)$ mice, but fully reverse paclitaxelinduced mechanical allodynia in $\mathrm{CB}_{2}(+/+)$ animals. The $\mathrm{CB}_{2}$ receptor antagonist SR144528 blocks the antiallodynic effects of JZL184 and MJN110. Control (Ctrl) mice and vehicle (Veh) treatment groups are shown for comparison. Data are reported as mean \pm S.E.M., $n=$ 8 mice/group. $* * * P<0.001$ vs. $\mathrm{CB}_{2}(+/+)$ mice $(\mathrm{A}) . * P<0.05, * * * P<$ 0.001 vs. vehicle pretreatment ( $\mathrm{B}$ and $\mathrm{C}$ ).

Conditioned Place Preference. An unbiased conditioned place preference paradigm was used to examine the effects of MJN110 in control mice and in paclitaxel-treated mice (Kota et al., 2007; Sanjakdar et al., 2015). Following at least 1 week of acclimation to the vivarium, mice were handled for 3 weeks leading up to CPP conditioning. A three-chamber design was used (two conditioning chambers with a central acclimation chamber; ENV3013; Med Associates, St Albans, VT). The outer chambers were $20 \times 20 \times$ $20 \mathrm{~cm}$ with differing flooring (white mesh or black rods) and wall coloring (white or black) to distinguish each. A small gray chamber in the middle connected to each outer chamber with a door.

This experiment consisted of four groups of mice in which each group received a cycle of paclitaxel or vehicle and then received conditioning sessions in which they were either administered vehicle each conditioning day or administered MJN110 or vehicle on alternating days. Eight days after the final paclitaxel injection, mice were placed in the central chamber and allowed to acclimate for 5 minutes. The doors to both chambers were then opened, and the mouse was allowed to explore the apparatus in a drug-free state for 15 minutes to record baseline chamber preferences. Beginning on postpaclitaxel day 9 , half the mice in each group received a single daily intraperitoneal injection of vehicle or MJN110 (5 mg/kg), alternating between these treatments each day for a total of eight conditioning sessions. MJN110 or vehicle was randomly assigned to either the black or white chamber at the start of the experiment to avoid potential bias. The other half of the mice received a single daily intraperitoneal injection of vehicle prior to each conditioning session. One hour after each injection, each mouse was placed in the appropriate conditioning chamber for 30 minutes. The day after the final conditioning session, each mouse was returned to the apparatus, but did not receive an injection and was allowed to move freely among the chambers for a 15-minute test period. Preference scores were calculated for MJN110 treatment based on the total amount of time spent in the MJN110-paired side (day 10, in seconds) minus the baseline preference (day 1, in seconds) for the same chamber. Paclitaxel- and vehicle-treated control mice (mice received vehicle paired to both chambers), the preference score was calculated as the average of the test preferences minus the baseline preference for each chamber.

Cell Culture. All lung cancer cells were maintained in Dulbecco's modified Eagle's medium (DMEM) supplemented with $10 \%(\mathrm{v} / \mathrm{v})$ fetal bovine serum (FB22-500HI; Serum Source International, Charlotte, $\mathrm{NC})$ and $1 \%(\mathrm{v} / \mathrm{v})$ combination of $10,000 \mathrm{U} / \mathrm{ml}$ penicillin and 10,000 $\mu \mathrm{g} / \mathrm{ml}$ streptomycin (15140-122, Pen/Strep; Thermo Fisher Scientific, Carlsbad, CA). Cells were incubated at $37^{\circ} \mathrm{C}$ under a humidified, $5 \%$ $\mathrm{CO}_{2}$ atmosphere. The $\mathrm{H} 460$ NSCLC cell line was generously provided by the laboratory of Dr. Richard Moran at VCU, and the A549 NSCLC cell line was a gift from the laboratory of Dr. Charles Chalfant at VCU.

Paclitaxel (50 nM) and JZL184 (1 $\mu \mathrm{M})$ were dissolved in DMSO, diluted with sterile PBS, and added to the medium to obtain the desired concentrations; less than $0.1 \%$ DMSO was present in the medium. This concentration of JZL184 was chosen as it inhibits MAGL in cancer cells (Nomura et al., 2010). All experiments using DMSO were performed in the dark.

Assessment of Cell Viability. The NSCLC cells were exposed to JZL184, paclitaxel, or a combination of JZL184 and paclitaxel for 24 hours, after which the drugs were removed and replaced with fresh medium. The number of viable cells was determined via trypan blue exclusion on days $1,3,5$, and 7 posttreatment. Cells were incubated with trypsin (0.25\% trypsin-EDTA) for 3 minutes and stained with trypan blue (15250; Invitrogen, Carlsbad, CA). The viable unstained cells were counted using a hemocytometer with bright-field microscopy.

Assessment of Apoptosis. Flow cytometry analyses were performed using BD FACSCanto II (BD Biosciences, San Jose, CA) and BD FACSDiva software at the Virginia Commonwealth University Flow Cytometry Core facility. For all studies, 10,000 cells per replicate within the gated region were analyzed. When collecting samples, both adherent and floating cells were harvested with $0.1 \%$ trypsin-EDTA and neutralized with medium after 48 hours of drug exposure. For quantification of apoptosis, cells were centrifuged and washed with PBS, then resuspended in $100 \mu \mathrm{l}$ of $1 \times$ binding buffer with $5 \mu \mathrm{l}$ of Annexin V and $5 \mu \mathrm{l}$ of propidium iodide (556547, FITC Annexin V Apoptosis Detection Kit; BD Biosciences). The samples were then incubated at room temperature while protected from light for 15 minutes. The suspension solution was then brought up to $500 \mu \mathrm{l}$ using the $1 \times$ binding buffer and analyzed by flow cytometry.

Statistical Analyses. Results are reported as the mean \pm S.E.M. and were prepared using GraphPad Prism $7 . \mathrm{ED}_{50}$ values were calculated as previously described (Grim et al., 2017). Briefly, data were converted to \% maximal positive effect (average maximum and minimum values for drug treatment) for each cohort and plotted versus log dose values. $\mathrm{ED}_{50}$ values and $95 \%$ confidence limits were 
A MCP-1, Dorsal Root Ganglia

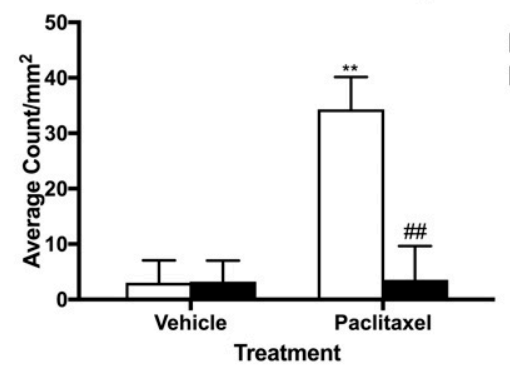

B

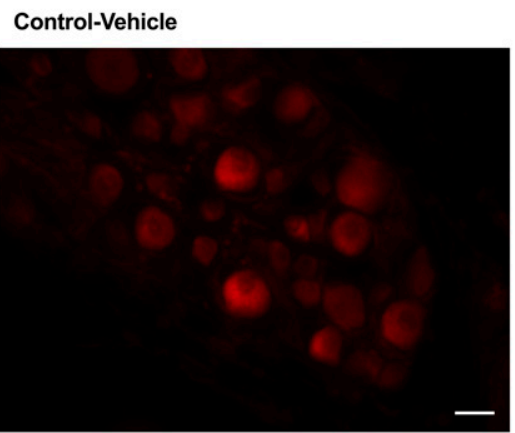

Paclitaxel-Vehicle

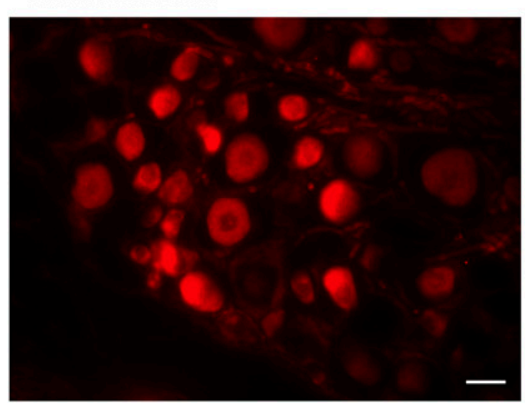

Paclitaxel-MJN110

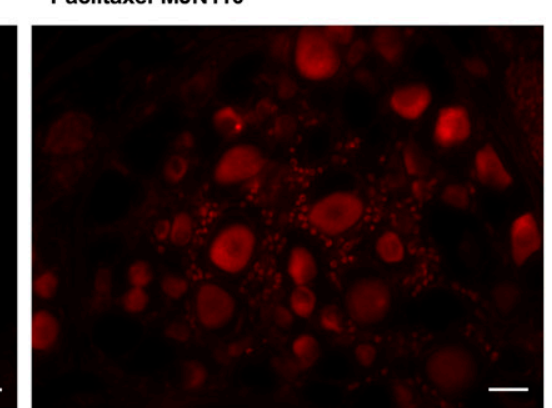

Fig. 4. MJN110 attenuates paclitaxel-induced MCP-1 expression in the dorsal root ganglia. (A) Nine days after a cycle of paclitaxel, vehicle-treated mice show a significant increase of MCP-1 expression in lumbosacral dorsal root ganglia compared with control mice that did not receive paclitaxel. MJN110 significantly blocks paclitaxelinduced increases of MCP-1 expression. (B) Representative dorsal root ganglia image for each of the four treatment conditions. All images are at $40 \times$. Scale bar, $10 \mu \mathrm{m}$. Data are reported as mean \pm S.E.M., $n=$ 4 mice/group. $* * P<0.01$ vs. vehicle-treated mice that did not receive paclitaxel. \#\#P $<0.01$ vs. vehicle-treated mice that received paclitaxel.
Control-MJN110

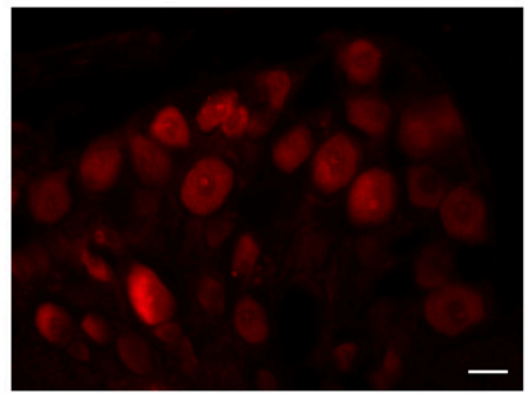

calculated using a linear regression analysis. Potency ratios were calculated based on the distance between the two dose-response curves with $95 \%$ confidence limits. Based on the study design, a oneor two-way analysis of variance (ANOVA) was used to identify statistical differences followed by Holm-Sidak post hoc testing of significant ANOVAs. Dunnett's test was used when comparing all treatments to a single control group in the dose-response studies. A within-subjects design was used for studies involving genetic knockouts, MJN110 time course, KT-195 time course, and MJN110 antagonism studies. A repeated-measures ANOVA was used specifically for time course studies and when comparing paw withdrawal thresholds pre- and postpaclitaxel. Unpaired $t$ tests were used to compare two groups when indicated. Unless otherwise noted, prepaclitaxel/vehicle baseline allodynia values were not included in statistical analysis ( $n=7$ to 8 for all allodynia studies; $n=15$ to 16 per group for CPP studies; $n=4$ for immunohistochemistry studies). Grubbs' test was used to remove any significant outliers from each group in the CPP studies only. For all experiments, the probability of a type I error $(\alpha)$ was set to $5 \%$ with $P$ values of $<0.05$ considered significant.

\section{Results}

MAGL Inhibitors Reverse Paclitaxel-Induced Mechanical Allodynia in Dose- and Time-dependent Manners. Mice undergoing a paclitaxel cycle regimen displayed significant mechanical allodynia relative to control mice within 24 hours following the final injection [main interaction of drug $\times F(1,13)=8.71, P<0.05$; Supplemental Fig. 1]. JZL184 (40 mg/kg, i.p.) significantly reversed paclitaxel-induced mechanical allodynia [main interaction of drug $\times$ time, $F(7,98)=9.50, P<0.001]$ for up to 5 hours (Fig. 1A). Similarly, MJN110 (5 mg/kg, i.p.) reversed mechanical allodynia compared with vehicle treatment [main interaction of drug $\times$ time, $F(7,98)=6.83, P<0.001$ ] for up to 5 hours postadministration (Fig. 1B). In mice that did not receive paclitaxel, JZL184 (40 mg/kg) altered paw withdrawal thresholds [main interaction of drug $\times$ time, $F(7,98)=2.204 ; P<$ 0.05]; however, post hoc analysis did not reveal any significant differences compared with vehicle up to 24 hours posttreatment (Supplemental Fig. 2A). In vehicle control mice, MJN110 (5 $\mathrm{mg} / \mathrm{kg}$ ) did not significantly alter von Frey withdrawal thresholds (main effect of time, $P=0.48$; main effect of drug, $P=0.61$; interaction, $P=0.96$; Supplemental Fig. $2 \mathrm{~B}$ ). To control for ABHD6 inhibition, an off-target effect of MJN110 (Niphakis et al., 2013), KT-195 (40 mg/kg) was administered to paclitaxel- and control vehicle-treated mice. KT195 did not alter paw withdrawal thresholds in either paclitaxel-treated $(P>0.3)$ or control animals $(P>0.3$; Supplemental Fig. 3$)$.

The mechanical antiallodynic dose-response relationships of JZL184 and MJN110 from separate cohorts of mice are 
A

MCP-1, Dorsal Horn

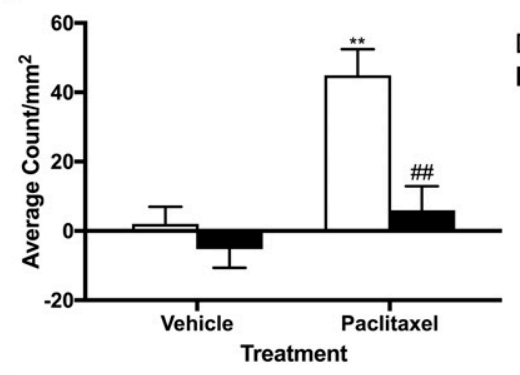

Vehicle

MJN110

B

Vehicle-Vehicle

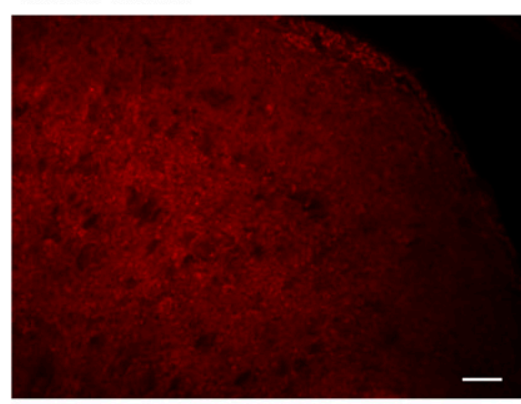

Vehicle-MJN110

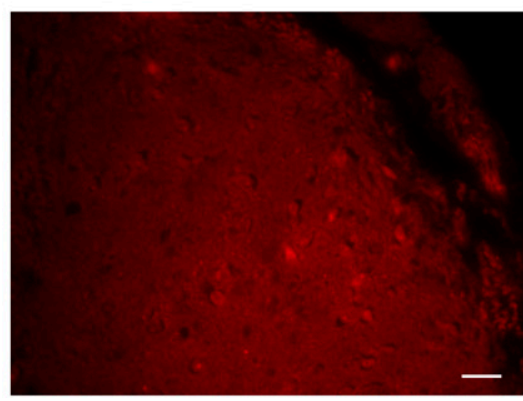

Paclitaxel-Vehicle

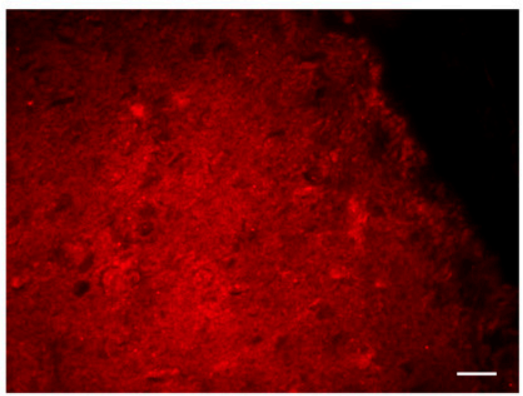

Paclitaxel-MJN110

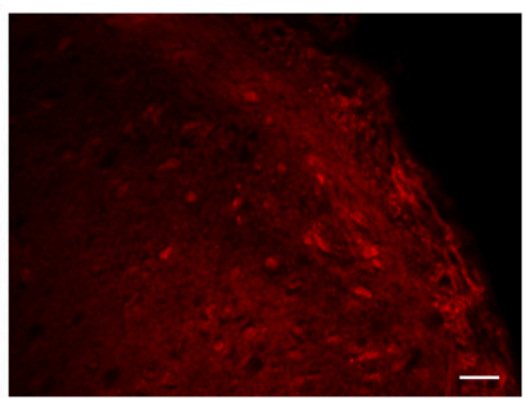

Fig. 5. MJN110 attenuates paclitaxel-induced MCP-1 expression in the dorsal horn of the spinal cord. (A) A cycle of paclitaxel elicits a significant increase in MCP-1 expression in lumbosacral spinal cord compared with control mice that did not receive paclitaxel. MJN110 $(5 \mathrm{mg} / \mathrm{kg}$ ) reverses paclitaxel-induced elevations of MCP-1 expression. (B) Representative image for each of the four conditions. All images are at $40 \times$. Scale bar, $10 \mu \mathrm{m}$. Data are reported as mean \pm S.E.M., $n=4$ mice/group. ${ }^{*} * P<$ 0.01 vs. vehicle-treated mice that did not receive paclitaxel. $\# \# P<0.01$ vs. vehicle-treated mice that received paclitaxel.

depicted in Fig. 1C. JZL184 significantly reversed paclitaxelinduced allodynia $[F(5,42)=5.74, P<0.001]$, with 16 and $40 \mathrm{mg} / \mathrm{kg}$. JZL184 significantly differing from the vehicle condition. JZL184 (40 $\mathrm{mg} / \mathrm{kg})$ fully reversed paclitaxelinduced allodynia and elicited similar von Frey thresholds as those from mice that did not receive paclitaxel $(t$ test, $P>$ 0.05). Similarly, MJN110 significantly reversed mechanical allodynia $[F(4,35)=4.83, P<0.01]$. MJN110 $(3$ and $5 \mathrm{mg} / \mathrm{kg})$ significantly differed from vehicle. MJN110 (5 mg/kg) fully reversed paclitaxel-induced allodynia to withdrawal thresholds comparable to control mice not treated with paclitaxel $(t$ test, $P>0.05$ ). The respective $\mathrm{ED}_{50}$ values (95\% confidence limits) for JZL184 and MJN110 were $8.4(5.2-13.6)$ and 1.8 (1.0-3.3) $\mathrm{mg} / \mathrm{kg}$. MJN110 was 4.7 (2.0-10.6; 95\% confidence limits) times more potent than JZL184.

Antiallodynic Effects of MAGL Inhibitors Require CB $_{1}$ Receptors. A cycle of paclitaxel elicited significant mechanical allodynia in both $\mathrm{CB}_{1}(+/+)$ and (-/-) mice [main effect of paclitaxel, $F(1,14)=144.2, P<0.001]$ with no significant main effects of genotype $(P=0.06)$ and no significant interaction between genotype and paclitaxel treatment $(P=0.18$; Fig. 2A). Allodynia was stable during the 4 weeks of behavioral assessment. JZL184 significantly reversed paclitaxel-induced allodynia in $\mathrm{CB}_{1}(+/+)$ mice, but not in $\mathrm{CB}_{1}(-/-)$ mice [interaction of drug $\times$ genotype, $F(1,26)=$ 8.316, $P<0.01$; Fig. 2A]. Similarly, MJN110 significantly reversed allodynia in $\mathrm{CB}_{1}(+/+)$ mice, and not in $\mathrm{CB}_{1}(-/-)$ mice [interaction of drug $\times$ genotype, $F(1,28)=5.574, P<$ 0.05; Fig. 2A].

By using a complementary pharmacologic approach, the $\mathrm{CB}_{1}$ receptor antagonist rimonabant $(3 \mathrm{mg} / \mathrm{kg})$ or vehicle was administered 30 minutes before each respective MAGL inhibitor. As shown in Fig. 2B, rimonabant blocked the antiallodynic effects of JZL184 but had no effects on its own [interaction of antagonist $\times$ drug, $F(1,28)=11.56, P<0.01$ ]. Similarly, rimonabant blocked the antiallodynic effects of MJN110 $[F(1,28)=40.0, P<0.001$; Fig. 2C]. However, rimonabant did not affect von Frey threshold in control mice that did not receive a cycle of paclitaxel ( $t$ test, $P>0.05$ ) (Fig. 2, B and C).

Antiallodynic Effects of MAGL Inhibitors Require $\mathbf{C B}_{2}$ Receptors. $\mathrm{CB}_{2}(+/+)$ and (-/-) mice developed significant mechanical allodynia after a cycle of paclitaxel [main effect of paclitaxel, $F(1,14)=113.8, P<0.001]$ with no difference between genotypes $(P=0.35$ ) (Fig. 3A), and allodynic responses remained stable throughout the 5-week behavioral assessment period. JZL184 [interaction of drug $\times$ genotype, $F(1,28)=21.8, P<0.001$; Fig. 3A] as well as MJN110 
A phospho-p38 MAPK, Dorsal Root Ganglia

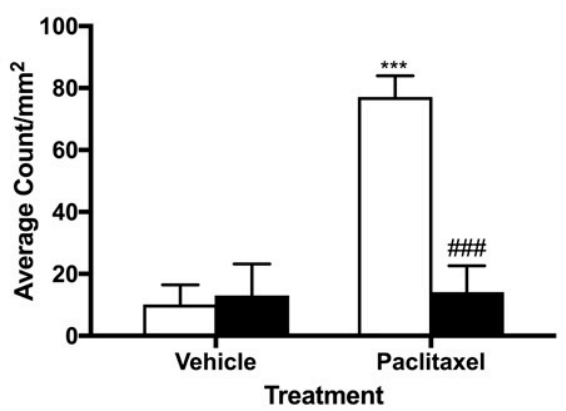

B

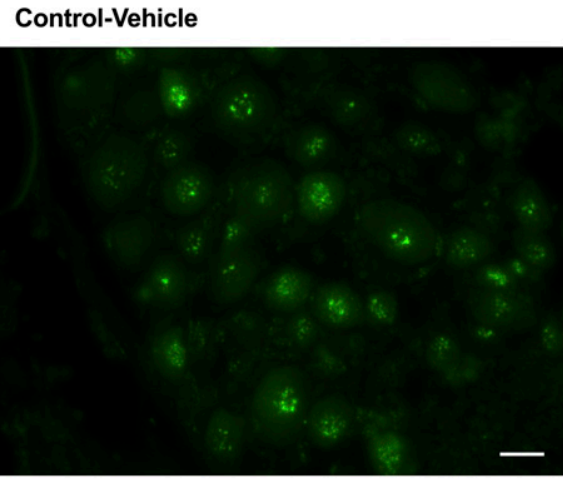

Paclitaxel-Vehicle

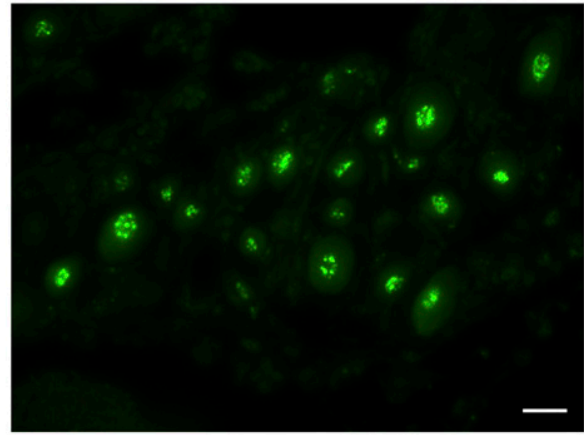

Paclitaxel-MJN110
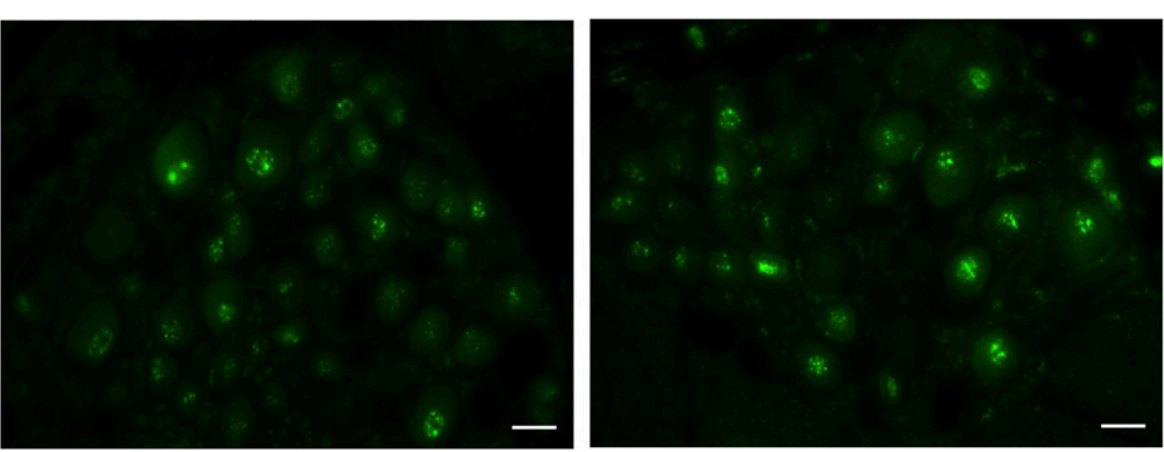

Vehicle

MJN110
Fig. 6. MJN110 attenuates paclitaxel-induced phospho-p38 MAPK expression in the dorsal root ganglia. (A) Following paclitaxel treatment, vehicle-treated mice show a significant increase of phospho-p38 expression in lumbosacral dorsal root ganglia compared with control mice that did not receive paclitaxel. MJN110 significantly decreased paclitaxel-induced expression of phospho-p38. (B) Representative dorsal root ganglia image for each of the four conditions. All images are at $40 \times$. Scale bar, $10 \mu \mathrm{m}$. Data are reported as mean \pm S.E.M., $n=4$ mice/group. $* * * P<0.001$ vs. vehicle-treated mice that did not receive paclitaxel. \#\#\#P $<0.001$ vs. vehicletreated mice that received paclitaxel.
$[\mathrm{F}(1,28)=9.491, P<0.01 ;$ Fig. 3A] significantly reversed paclitaxel-induced mechanical allodynia in $\mathrm{CB}_{2}(+/+)$ and not in $\mathrm{CB}_{2}(-/-)$ mice.

In the next experiment, we tested whether a $\mathrm{CB}_{2}$ receptor antagonist would block the antinociceptive effects of these MAGL inhibitors. SR144528 (3 mg/kg, i.p.) or vehicle was administered 30 minutes prior to JZL184 or MJN110. As shown in Fig. 3B, SR144528 blocked the antiallodynic effects of JZL184 and lacked effects on its own [interaction of antagonist $\times$ drug, $F(1,28)=12.33, P<0.01]$. Similarly, SR144528 blocked the antiallodynic effects of MJN110 [interaction of antagonist $\times \operatorname{drug}, F(1,28)=9.43, P<0.01$; Fig. 3C]. Although SR144528 produced a significant but small reduction in paw withdrawal thresholds in control mice in the JZL184 experiment (Fig. 3B), it did not affect thresholds in control mice in the MJN110 experiment (Fig. 3C).

MJN110 Attenuates MCP-1 and Phospho-p38 Expression in Paclitaxel-Treated Mice. As paclitaxel causes inflammatory responses in DRG (Li et al., 2015; Zhang et al., 2016) and spinal cord (Pevida et al., 2013; Zhang et al., 2013), we evaluated whether a MAGL inhibitor would attenuate this inflammation at 3 hours, a time point corresponding to allodynia reversal. A cycle of paclitaxel led to a significant increase in MCP-1 expression in the DRG compared with mice that did not receive paclitaxel [interaction of paclitaxel treatment $\times$ MJN110 treatment, $F(1,12)=9.426$, $P<0.05$; post hoc: $P<0.01$; Fig. 4]. Treatment with MJN110 (5 $\mathrm{mg} / \mathrm{kg}$ ) significantly decreased MCP-1 expression in paclitaxel-treated mice $[P<0.01]$, but not in the control vehicle-treated mice $[P=1.0$ for comparison between paclitaxel-MJN110 and control-vehicle mice]. Paclitaxel also increased MCP-1 expression in the spinal dorsal horn, an effect that was attenuated by MJN110 pretreatment versus vehicle $[F(1,12)=6.294, P<0.05$; post hoc $P<0.01$; Fig. 5]. MJN110 significantly decreased spinal MCP-1 expression in paclitaxel-treated mice to levels comparable to control-vehicle mice $(P=0.68)$.

Mice given a cycle of paclitaxel also demonstrated significantly increased phospho-p38 expression in the DRG compared with control mice, and this effect was inhibited by 


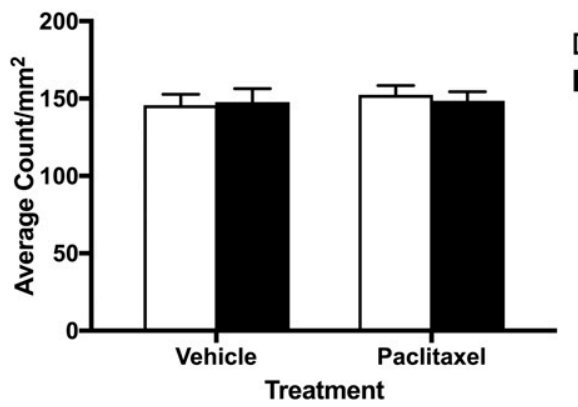

B

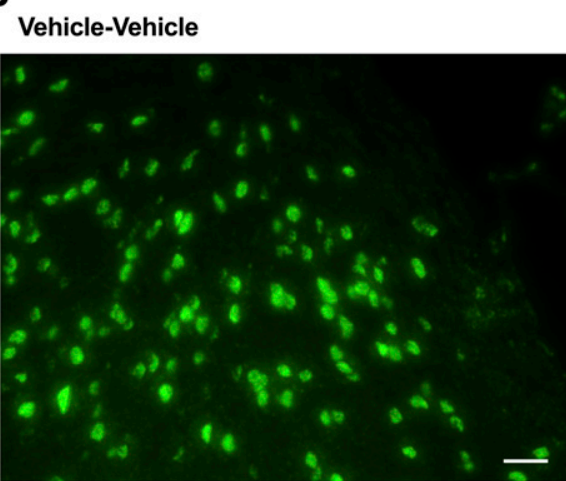

Paclitaxel-Vehicle

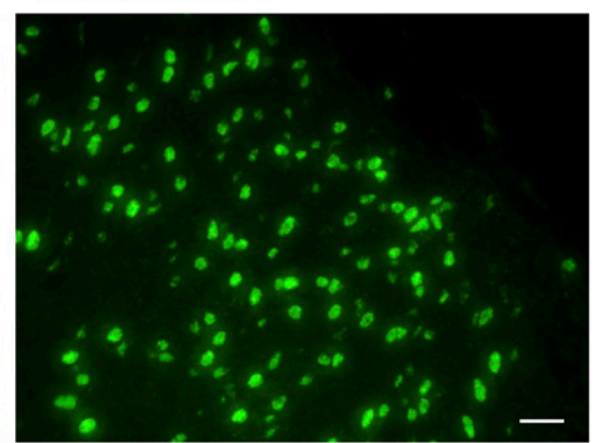

Fig. 7. Paclitaxel does not increase phosphop38 expression in the spinal dorsal horn. (A) Neither paclitaxel nor MJN110 alters phosphorylated phospho-38 MAPK expression in the spinal dorsal horn. (B) Representative images for each condition. All images are at $40 \times$. Scale bar, $10 \mu \mathrm{m}$. Data are reported as mean \pm S.E.M., $n=4$ mice/group.

Vehicle-MJN110

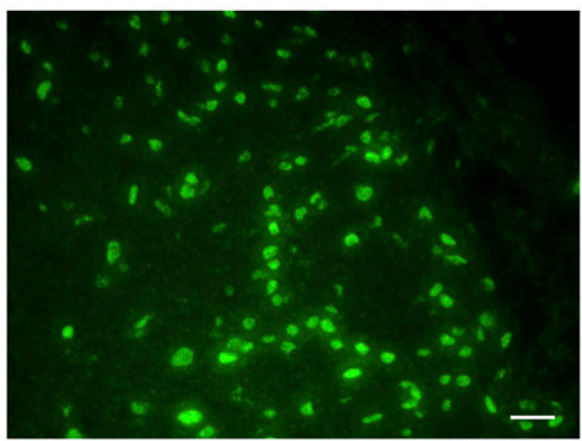

Paclitaxel-MJN110

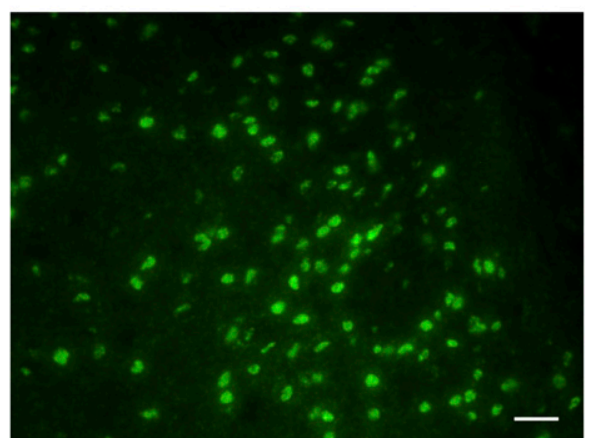

MJN110 [interaction of paclitaxel treatment $\times$ MJN110 treatment, $F(1,12)=16.56, P<0.01$; Fig. 6]. MJN110 significantly decreased DRG phospho-p38 expression in paclitaxel-treated mice to levels comparable to controlvehicle mice $(P=0.98)$. However, there were no significant changes in the expression of phospho-p38 MAPK in the spinal dorsal horn (no main effect of paclitaxel, $P=0.60$; no main effect of MJN110, $P=0.90$; Fig. 7). Qualitative confocal microscopy of DRG showed that MCP-1 and phospho-p38 expression colocalizes in neurons and cells consistent with the location of satellite cells as indicated by the nuclear marker DAPI (Fig. 8).

Repeated Administration of Low-dose JZL184 Produces Sustained Antiallodynic Effects and Increases 2-AG Levels in the Lumbar Spinal Cord. Figure 9A outlines the treatment procedure depicting the consequences of acute and repeated administration of $4 \mathrm{mg} / \mathrm{kg}$ (threshold dose) and $40 \mathrm{mg} / \mathrm{kg}$ (high dose) JZL184. These treatments produced statistically significant differential effects on paclitaxel-induced allodynia $[F(5,42)=8.38, P<0.001$;
Fig. 9B]. Acute administration of $40 \mathrm{mg} / \mathrm{kg}$ JZL184 fully reversed paclitaxel-induced allodynia $(P<0.01)$, but this effect underwent tolerance following 6 days of daily administration $(P=1.0)$. In contrast, whereas acutely administered $4 \mathrm{mg} / \mathrm{kg}$ JZL184 did not significantly attenuate paclitaxelinduced allodynia $(P=1.0)$, repeated administration of this dose fully reversed the allodynia $(P<0.05)$.

Following mechanical allodynia assessment, mice were euthanized and the L4-L6 level of the lumbar spinal cord was procured for lipid quantification. As depicted in Fig. 10A, JZL184 significantly elevated 2 -AG levels $[F(5,42)=81.37$, $P<0.001]$. While acute $(P<0.001)$ and repeated $(P<0.001)$ administration of $40 \mathrm{mg} / \mathrm{kg}$ JZL184 elevated 2-AG levels, $4 \mathrm{mg} / \mathrm{kg}$ JZL184 significantly increased 2-AG spinal levels following repeated produced administration $(P<0.001)$, but not acute administration $(P=0.09)$. Repeated administration of $40 \mathrm{mg} / \mathrm{kg}$ JZL184 led to higher 2-AG levels than acute treatment $(P<0.001)$. A significant effect was also found for spinal AEA levels $[F(5,42)=19.25, P<0.001]$. Repeated administration of either $4 \mathrm{mg} / \mathrm{kg}(P<0.05)$ or $40 \mathrm{mg} / \mathrm{kg}$ 


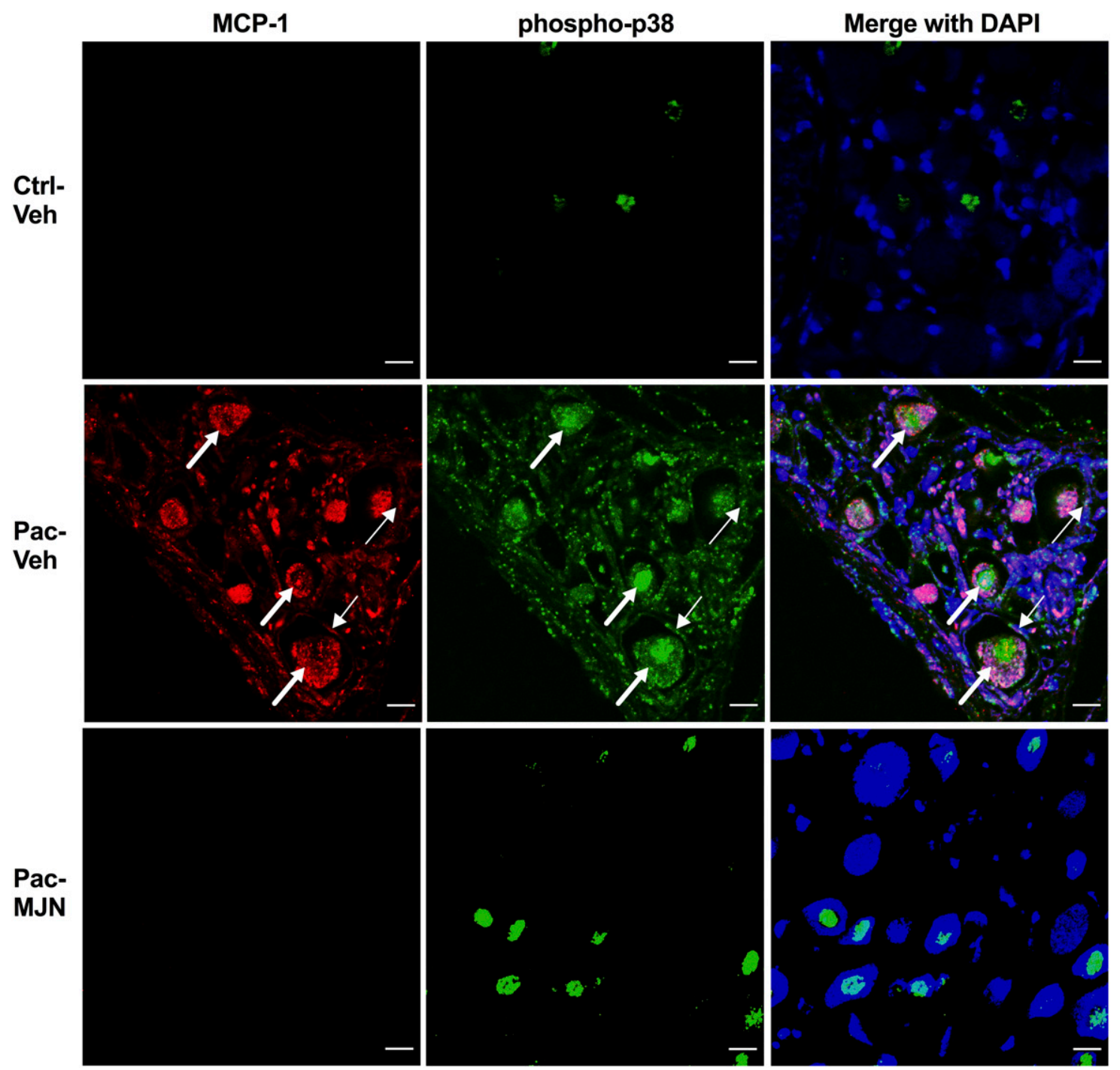

Fig. 8. Qualitative confocal microscopy of MCP-1 and phospho-p38 MAPK colocalization in dorsal root ganglia cells. A cycle of paclitaxel (Pac) increased MCP-1 (left) and phospho-p38 (middle) expression compared with control vehicle (Ctrl) treatment. MCP-1 and phospho-p38 colocalize in cells stained with the nuclear marker DAPI (right). Thick arrows indicate neurons, and thin arrows indicate cells consistent with the location of satellite cells. This colocalization is not observed in sections from MJN110 (MJN)-treated mice compared with vehicle (Veh) treatment. All images are at $63 \times$. Scale bar, $10 \mu \mathrm{m}$.

$(P<0.001)$ JZL184 (Fig. 10B) produced significant increased spinal AEA levels. As shown in Fig. 10C, a significant effect was found for arachidonic acid spinal levels $[F(5,42)=6.238$, $P<0.001$ ). However, repeated administration of $40 \mathrm{mg} / \mathrm{kg}$ JZL184 was the only condition significantly different from the control condition $(P<0.01)$. Finally, a significant effect was found for $\mathrm{PGD}_{2}[F(5,42)=4.591, P<0.01$; Fig. 10D]. Post hoc analysis revealed that paclitaxel-treated mice given repeated administration of $40 \mathrm{mg} / \mathrm{kg}$ JZL184 possessed lower spinal $\mathrm{PGD}_{2}$ levels in mice given repeated administration of $40 \mathrm{mg} / \mathrm{kg}$ JZL184 than vehicle control mice that did not receive paclitaxel $(P<0.001)$ and mice given an acute injection of $4 \mathrm{mg} / \mathrm{kg}$ JZL184 $[P=0.03]$. Compared with vehicle control mice, paclitaxel treatment did not alter 2-AG $(P=0.98)$, AEA $(P=0.95)$, arachidonic acid $(P=0.81)$, or $\mathrm{PGD}_{2}(P=0.52)$ levels in the lumbar spinal cord.

MJN110 Produces a Conditioned Place Preference in Paclitaxel-Treated Mice. In the next study, we examined whether a MAGL inhibitor produces a CPP in vehicle-treated or paclitaxel-treated mice (see Fig. 11A for a schematic depicting the experimental procedure). MJN110 produced a significant place preference in paclitaxel-treated mice, but did not affect place conditioning in control mice [interaction of paclitaxel treatment $\times$ MJN110 treatment, $F(1,59)=4.338$, $P<0.05$; Fig. 11B]. As confirmed in Supplemental Fig. 4, paclitaxel-treated mice had significantly lower withdrawal thresholds than vehicle-treated mice both before and after CPP training and testing ([interaction of paclitaxel treatment $\times$ time, $F(2,122)=61.54, P<0.001$ ]

JZL184 Does Not Interfere with Paclitaxel-Induced Growth Arrest or Apoptosis in Non-Small Cell Lung Cancer Cells. The final experiment examined whether JZL184 interferes with paclitaxel-induced growth arrest of two human NSCLC lines or has effects on its own. Consistent with its known antiproliferative actions, paclitaxel decreased the number of viable A549 cells [interaction of treatment $\times$ 
A

A Paclitaxel

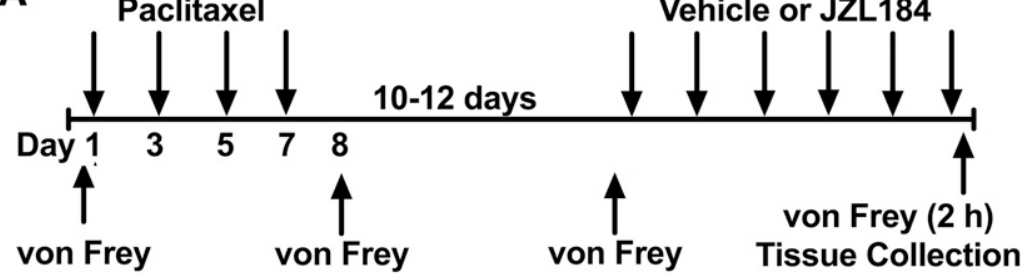

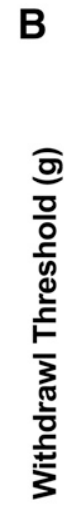

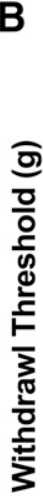

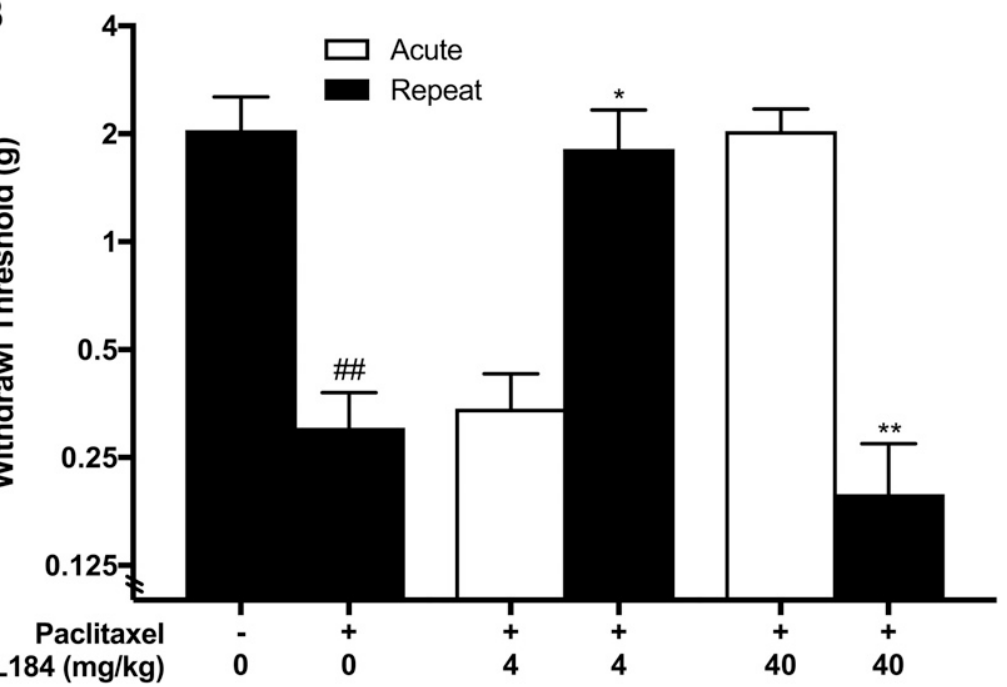

Fig. 9. Acute and repeated administration of 4 and $40 \mathrm{mg} / \mathrm{kg}$ JZL184 differentially affect paclitaxel-induced allodynia. (A) Experimental procedural timeline. (B) Although acute administration of high-dose JZL184 fully reverses paclitaxel-induced allodynia, this antinociceptive effect undergoes tolerance following 6 days of daily JZL184 Whereas acute administration of low-dose JZL184 does not attenuate paclitaxel-induced allodynia, it completely reverses allodynia after repeated administration. All data were recorded 2 hours after the last treatment. Data are reported as mean \pm S.E.M., $n=8$ mice/group. ${ }^{*} P<0.05$ $* * P<0.01$ vs. the corresponding acute condition; \#\#P< 0.01 vs. no paclitaxel. day, $F(12,32)=10.4, P<0.001$; Fig. 12A]. JZL184 did not affect viable cell number alone $(P=0.94$ compared with control, day 7$)$ or in combination with paclitaxel $(P=0.98$ compared with paclitaxel alone; Fig. 12A). Paclitaxel also decreased the number of viable $\mathrm{H} 460$ cells [interaction of treatment $\times$ day, $F(12,32)=115, P<0.001$; Fig. 12B], and
JZL184 did not affect viable cell number alone $[P=0.93$ compared with control, day 7] or in combination with paclitaxel $[P=0.93$ compared with paclitaxel alone]. Likewise, JZL184 did not affect apoptotic cell population. Paclitaxel produced apoptosis in both A549 cells [main effect of paclitaxel, $F(1,8)=194.4, P<0.001$; Fig. 13A] and H460 cells
A
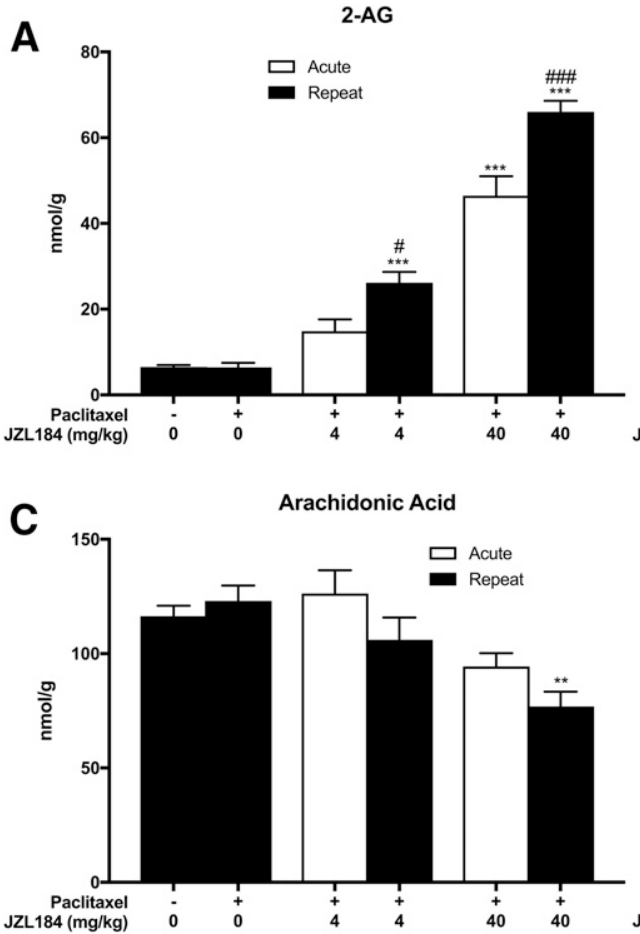
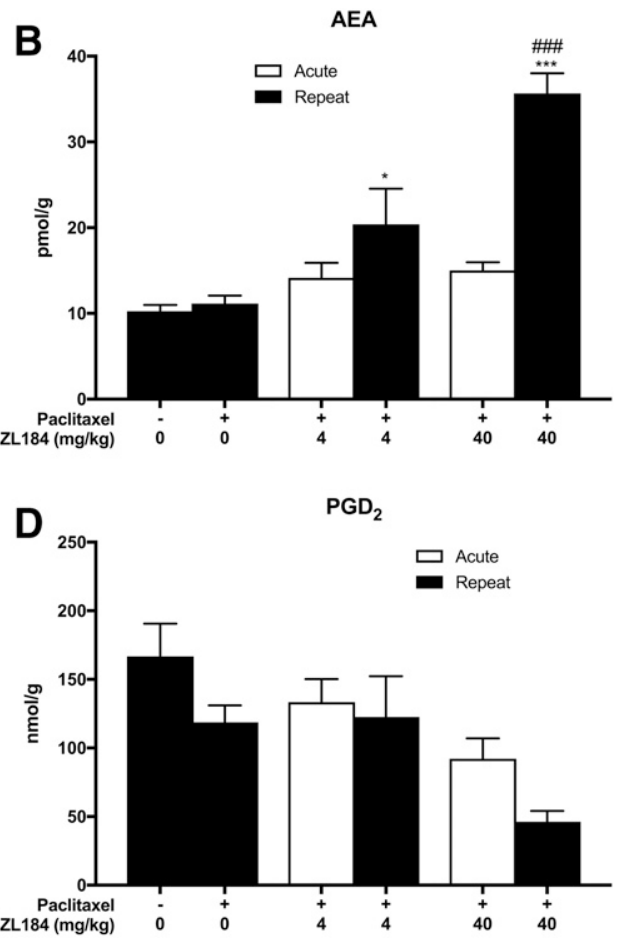

Fig. 10. Acute vs. repeated administration of JZL184 (4 or $40 \mathrm{mg} / \mathrm{kg}$ ) on 2 -AG (A), anandamide (AEA) (B), arachidonic acid $(\mathrm{C})$, and prostaglandin $\mathrm{D} 2\left(\mathrm{PGD}_{2}\right)(\mathrm{D})$ in spinal cord. Data are reported as mean \pm S.E.M., $n=8$ mice/group. ${ }^{*} P<0.05$ $* * P<0.01 ; * * * P<0.001$ vs. paclitaxelvehicle. $\# P<0.05 ; \# \# P<0.001$ vs. the corresponding acute treatment. 


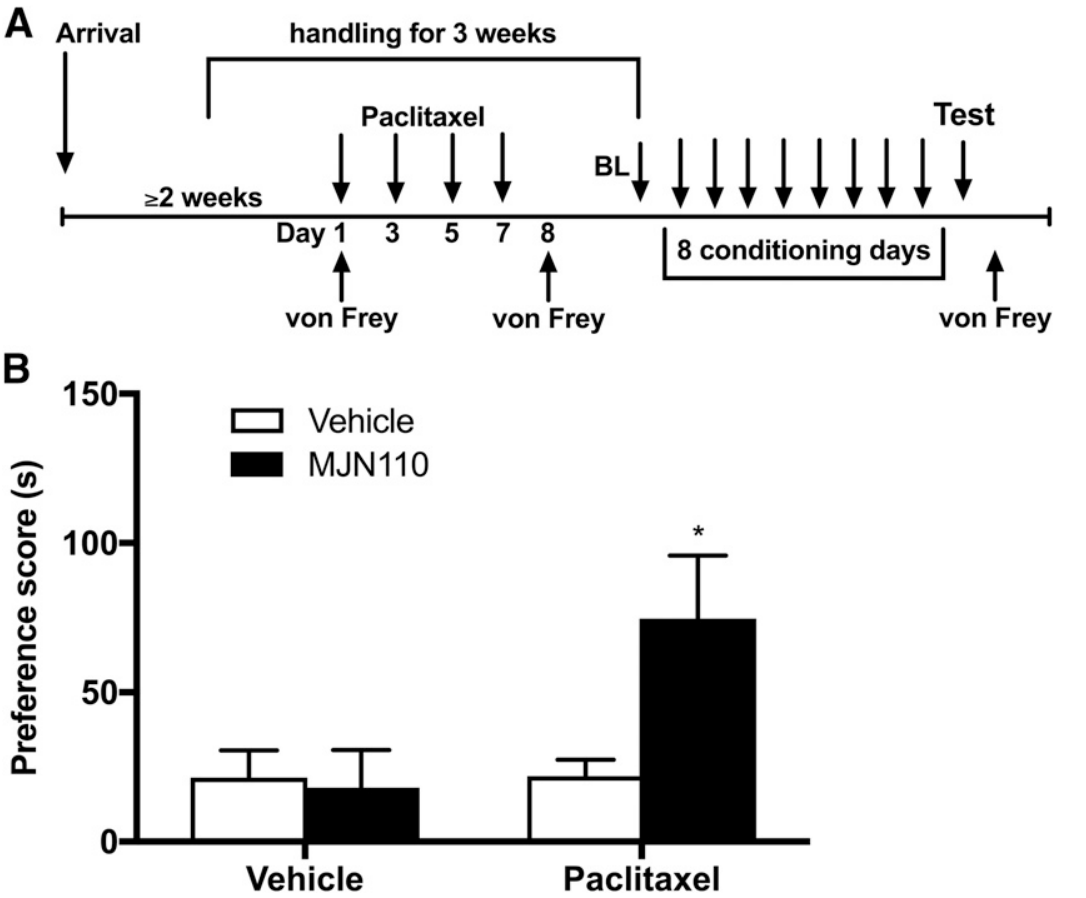

Fig. 11. A MAGL inhibitor produces a conditioned place preference in paclitaxel-treated mice. (A) Conditioned place preference procedure. (B) MJN110 (5 mg/kg) leads to the development of a CPP in paclitaxel-treated mice, but not in mice that received a cycle of vehicle a CPP in paclitaxel-treated. BL, baseline preference test prior to conditioning. Test, drug-free preference test after conditioning. Data are reported as mean \pm S.E.M., $n=15$ or 16 mice/group. ${ }^{*} P<0.05$ MJN110 vs. vehicle control in paclitaxel mice.

[main effect of paclitaxel, $F(1,8)=7.549, P<0.03$; Fig. 13B]. JZL184 did not interfere with paclitaxel-induced apoptosis and had no effect on its own in either A549 (no main effect of JZL184 treatment, $P=0.59$ ) or H460 (no main effect of JZL184 treatment, $P=0.60)$ cells.

\section{Discussion}

The present study replicates and extends the results of other studies showing that the MAGL inhibitor JZL184 reverses paclitaxel-induced (Slivicki et al., 2017) and cisplatin-induced (Guindon et al., 2013) allodynia. Here, we demonstrate that JZL184 and MJN110 fully reverse paclitaxel-induced mechanical allodynia in a manner consistent with their respective MAGL inhibitory constant estimates of 8 and $2.1 \mathrm{nM}$ (Long et al., 2009; Niphakis et al., 2013). Notably, neither MAGL inhibitor produced enhanced or depressed paw withdrawal thresholds in control mice not given paclitaxel. To control for MJN110 inhibition of ABHD6, the ABHD6 inhibitor KT195 did not affect the allodynic effects of paclitaxel. The antiallodynic effects of each MAGL inhibitor required both $\mathrm{CB}_{1}$ and $\mathrm{CB}_{2}$ receptors, as demonstrated by genetic and pharmacologic approaches. MJN110 also attenuated paclitaxel-induced increases in phospho-p38 and MCP1/CCL2 expression, suggesting a concomitant decrease of inflammatory responses with allodynia reversal. Tolerance to the antiallodynic effects of repeated administration, noted after a high dose of JZL184, was not observed with a subthreshold dose regimen that produced antiallodynic effects and increased spinal 2-AG and anandamide levels following repeated administration. Furthermore, MJN110 produced a CPP in paclitaxel-treated mice, but not in control animals. Finally, we show that JZL184 treatment, at a concentration that inhibits MAGL (Nomura et al., 2010), does not interfere with the antiproliferative and apoptotic effects of paclitaxel in human cell lines of NSCLC.
Here we report that the antiallodynic effects of MJN110 and JZL184 in the paclitaxel neuropathic pain model requires activation of both $\mathrm{CB}_{1}$ and $\mathrm{CB}_{2}$ receptors. Likewise, both receptors are required for the antinociceptive effects of MAGL inhibitors in chronic constriction injury of the sciatic nerve (Ignatowska-Jankowska et al., 2015), carrageenan (Ghosh et al., 2013), and cisplatin (Guindon et al., 2013) models of pain. In contrast, selective $\mathrm{CB}_{2}$ receptor agonists fully reversed paclitaxel-induced allodynia (Rahn et al., 2008; Deng et al., 2015b). Similarly, pan $\mathrm{CB}_{1} / \mathrm{CB}_{2}$ receptor agonists (CP55,940; WIN55-212; $\Delta^{9}$-tetrahydrocannabinol) reverse paclitaxel-induced allodynia in rodents (Pascual et al., 2005; Deng et al., 2015a,b). The antiallodynic effects of CP55,940 in paclitaxel-treated mice show increased potency in $\mathrm{CB}_{2}(-/-)$ mice compared with $\mathrm{CB}_{1}(-/-)$ mice (Deng et al., 2015), demonstrating that sufficient stimulation of either receptor alone can elicit antinociceptive effects. Thus, MAGL inhibitors may require activation of both receptors because the degree to which they elevate 2 -AG may be insufficient to drive antiallodynic responses at either receptor alone.

Paclitaxel elicits neuronal damage in DRG followed later by satellite cell hypertrophy and macrophage infiltration (Peters et al., 2007). MCP-1 promotes macrophage recruitment (Zhang et al., 2016), and its expression in small nociceptive neurons sensitizes large- and medium-sized neurons by increasing intracellular calcium (Zhang et al., 2013). Paclitaxel also increases MCP-1 expression in the spinal dorsal horn from astrocytes (Zhang et al., 2013) as well as phosphorylates p38 through toll-like receptor 4 activation in DRG neurons, but not in the spinal cord ( $\mathrm{Li}$ et al., 2015). Phospho-p38 expression on small IB4- and CGRP-positive neurons (Li et al., 2015) leads to sodium channel activation and hyperexcitability of nociceptive neurons (Hudmon et al., 2008). Here, we confirmed that a cycle of paclitaxel induces MCP-1 expression in both the lumbosacral DRG and lumbar dorsal horn, whereas phospho-p38 is increased in the DRG, 
A

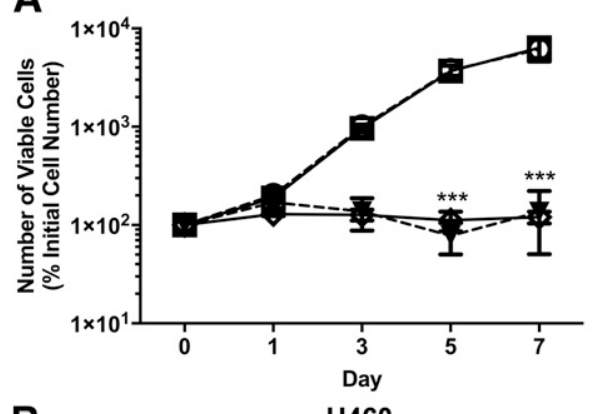

B

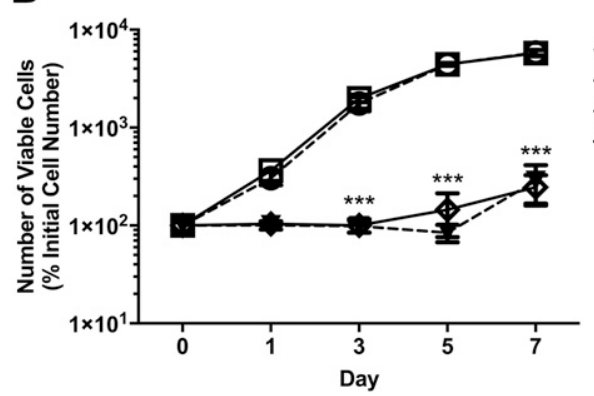

A
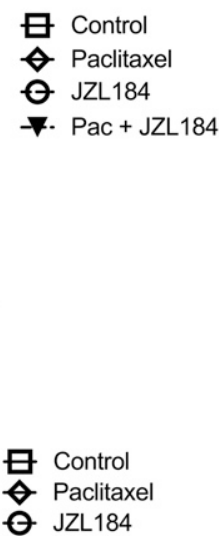
․ Pac + JZL184

Fig. 12. JZL184 does not stimulate non-small cell lung cancer (NSCLC) cell proliferation alone or interfere with paclitaxel (Pac, $50 \mathrm{nM}$ )-induced growth inhibition of A549 (A) or H460 (B) cells. Day 0 represents the initial number of cells after seeding. JZL184 (1 $\mu \mathrm{M})$, paclitaxel, or the combination of paclitaxel and JZL184 was added to the cultures on day 0 and was replaced with drug-free medium 24 hours later. The number of viable cells was determined via trypan blue exclusion. Data are expressed as the mean \pm S.E.M. of three independent experiments. ${ }^{* * *} P<0.001$ vs. control.

but not in the dorsal horn, as previously reported (Zhang et al., 2013; Li et al., 2015). As shown in Fig. 8, phospho-p38 and MCP-1 coexpression occurs in the same DRG neurons and cells consistent with the location of satellite cells. The findings that MJN110 attenuates paclitaxel-induced expression of phospho-p38 and MCP-1 suggest an anti-inflammatory action. However, it remains to be determined whether $\mathrm{CB}_{1}$ and/or $\mathrm{CB}_{2}$ receptors mediate these actions.

Whereas prolonged and complete blockade of MAGL leads to high brain levels of endocannabinoids, $\mathrm{CB}_{1}$ receptor downregulation and desensitization, and tolerance to the antinociceptive effects of MAGL inhibitors (Schlosburg et al., 2010), repeated administration of a low dose JZL184 produces elevated endocannabinoid brain levels without $\mathrm{CB}_{1}$ receptor functional tolerance (Kinsey et al., 2013). Similarly, the present study demonstrates that antiallodynic effects of high-dose JZL184 (40 mg/kg) in paclitaxel-treated mice undergo tolerance following repeated administration, but repeated administration of a subthreshold dose of JZL184 (4 mg/kg), which given acutely did not reverse allodynia, significantly elevated 2-AG and AEA in the L4-L6 region and fully reversed paclitaxel-induced allodynia. MAGL also contributes to the production of proinflammatory lipid mediators, such as arachidonic acid, prostanoids (Nomura et al., 2011b), and phosphatidic acids (Nomura et al., 2010), which could contribute to the antiallodynic actions of MAGL inhibitors. However, only repeated administration of high-dose JZL814 reduced arachidonic acid in the L4-L6 region of the spinal cord, and none of the JZL184 treatments significantly affected $\mathrm{PGD}_{2}$ compared with vehicle. Also, as paclitaxel leads to
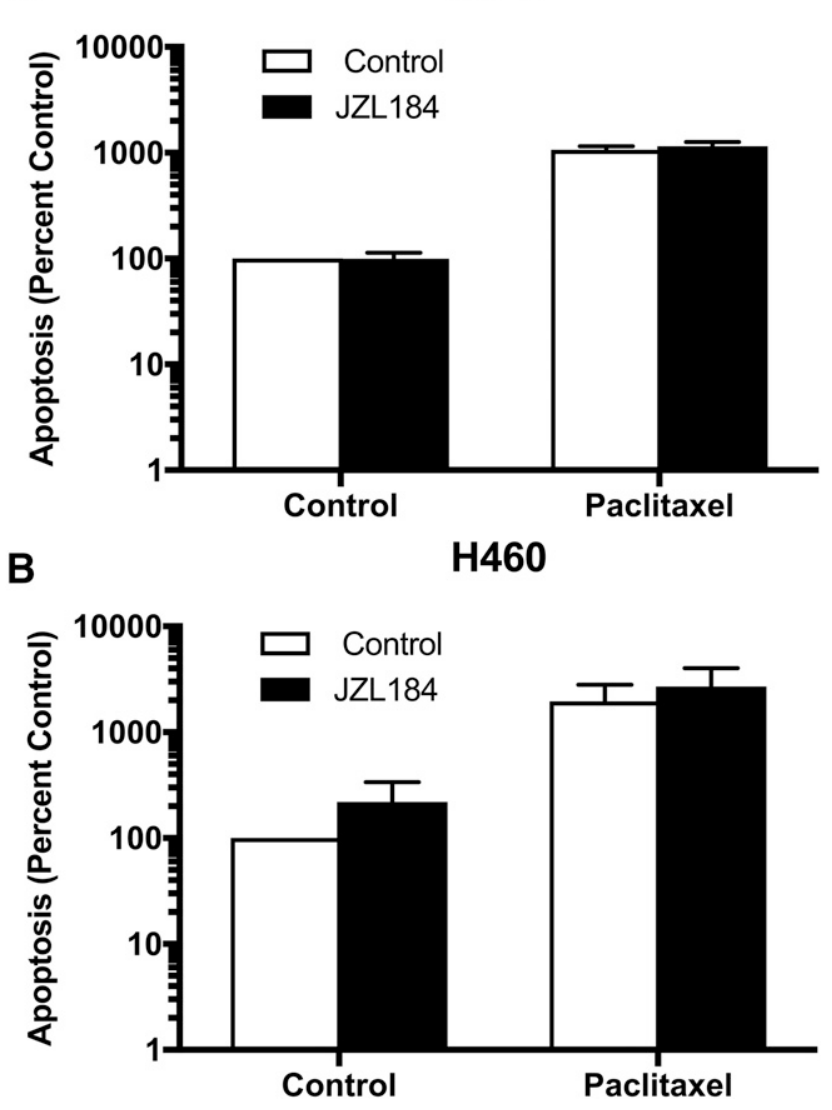

Fig. 13. JZL184 does not affect paclitaxel-induced apoptosis of non-small cell lung cancer (NSCLC) cells. A549 (A) and H460 (B) cells were exposed to JZL184 $(1 \mu \mathrm{M})$, paclitaxel $(100 \mathrm{nM})$, or the combination of paclitaxel and JZL184 for 48 hours. Quantification of apoptotic cells was determined using the Annexin V/PI assay, followed by flow cytometry analysis. Data are expressed as mean \pm S.E.M. of three independent experiments.

increased levels of lysophosphatidic acid in the spinal cord dorsal horn and lysophosphatidic acid receptor $1(-/-)$ and $3(-/-)$ mice show a phenotypic resistance to the development of paclitaxel-induced mechanical allodynia (Uchida et al., 2014), it is possible that MAGL inhibitors reduce this lipid as well as affect other mediators.

Although thermal, chemical, or mechanical stimuli are widely used to assess analgesia in rodents, these outcomes may lack clinical predictive value (Mogil, 2009). Alternatively, the CPP paradigm is used to infer potential affective aspects of pain relief into rodent pain models (King et al., 2009; Navratilova and Porreca, 2014; Havelin et al., 2016). Here, we make the unique observation that the MAGL inhibitor MJN110 produces a significant place preference in paclitaxeltreated mice, but not in control mice. This pattern of findings suggests that MJN110 lacks intrinsically rewarding or aversive effects, but is rewarding in paclitaxel-treated mice. The MJN110 data from control mice are consistent with the failure of JZL184 to produce a conditioned place preference or aversion (Gamage et al., 2015). The MJN110-induced CPP in paclitaxel-treated mice may represent a relief from affective or sensory aspects of nociception, as described in rodent models of cisplatin neuropathy (Park et al., 2013; Krukowski et al., 2017). However, MAGL inhibition may also relieve other 
aversive states in paclitaxel-treated mice, such as a preference for the dark chamber in the light/dark box test and increased immobility time in the forced swim test (Toma et al., 2017). As MAGL inhibitors produce pharmacological effects in laboratory animal assays used to screen antidepressant and anxiolytic drugs (Kinsey et al., 2011; Sciolino et al., 2011; Zhong et al., 2014), MJN110 chamber preference in paclitaxeltreated mice may represent relief from an aversive state distinct from neuropathy.

Because treatments for CIPN may be given while patients are still receiving chemotherapy, we tested if JZL184, at concentrations that inhibit MAGL (Nomura et al., 2010), interferes with paclitaxel-induced cell death or growth arrest. We found that paclitaxel decreases cell viability and induces apoptosis in two human cell lines of NSCLC, which were not altered by JZL184. In other cancer types (i.e., prostate, melanoma, ovarian), decreased MAGL expression or activity inhibited cell proliferation and transformation (Nomura et al., 2010, 2011a), although it is unclear whether A549 and H460 cells express MAGL. Taken together, these results suggest that inhibition of MAGL neither affects cancer growth alone nor interferes with the antiproliferative or antiapoptotic effects of paclitaxel in these in vitro models of NSCLC.

The results of the present study do not support the idea that the endogenous cannabinoid system contributes to the development of paclitaxel-induced allodynia. Consistent with previous findings (Deng et al., 2015a), a cycle of paclitaxel elicited sustained mechanical allodynia in both $\mathrm{CB}_{1}(-/-)$ and $\mathrm{CB}_{2}(-/-)$ mice and receptor antagonists of these receptors did not alter paclitaxel-induced allodynia. The finding that a cycle of paclitaxel did not alter 2-AG and AEA spinal levels approximately 2 weeks later is consistent with a previous study in which paclitaxel did not alter expression of $\mathrm{CB}_{1}$ receptor, $\mathrm{CB}_{2}$ receptor, MAGL, or FAAH mRNA levels in spinal cord (Deng et al., 2015b). In contrast, cisplatin-induced CIPN leads to increased spinal 2-AG and AEA levels (Guindon et al., 2013), suggesting that the endogenous cannabinoid system differentially responds to these chemotherapeutic agents. Nonetheless, as the present study examined only a single time point more than 2 weeks following paclitaxel treatment, a full-time course evaluation of spinal and DRG endocannabinoid levels would be of value.

The goal of this work was to test whether MAGL inhibition reverses paclitaxel-induced allodynia as well as markers of DRG neuroinflammation. As paclitaxel neuropathies are long lasting (Tanabe et al., 2013), substantially harm quality of life, and are difficult to treat (Kim et al., 2015), novel analgesic strategies are needed. The present study demonstrates that MAGL inhibitors attenuate paclitaxel nociceptive-related behaviors using both mechanical allodynia and the conditioned place preference paradigm. We also show that MAGL inhibition ameliorates MCP-1 and phospho-p38 expression in the DRG. Taken together, the findings of the present study suggest that MAGL represents a viable target for possible treatment of CIPN.

\section{Authorship Contributions}

Participated in research design: Curry, Wilkerson, Bagdas, Kyte, Patel, Donvito, Gewirtz, Damaj, Lichtman Cravatt.

Conducted experiments: Curry, Wilkerson, Bagdas, Mustafa, Kyte, Patel, Donvito, Poklis.

Contributed new reagents or analytic tools: Niphakis, Hsu, Cravatt.
Performed data analysis: Curry, Wilkerson, Bagdas, Mustafa, Kyte, Patel, Poklis.

Wrote or contributed to the writing of the manuscript: Curry, Wilkerson, Bagdas, Kyte, Donvito, Gewirtz, Damaj, Lichtman.

\section{References}

Bagdas D, Wilkerson JL, Kulkarni A, Toma W, AlSharari S, Gul Z, Lichtman AH, Papke RL, Thakur GA, and Damaj MI (2016) The $\alpha 7$ nicotinic receptor dual allosteric agonist and positive allosteric modulator GAT107 reverses nociception in mouse models of inflammatory and neuropathic pain. $\mathrm{Br} J$ Pharmacol 173: $2506-2520$.

Blankman JL, Simon GM, and Cravatt BF (2007) A comprehensive profile of brain enzymes that hydrolyze the endocannabinoid 2-arachidonoylglycerol. Chem Biol 14:1347-1356.

Bobylev I, Joshi AR, Barham M, Ritter C, Neiss WF, Höke A, and Lehmann HC (2015) Paclitaxel inhibits mRNA transport in axons. Neurobiol Dis 82:321-331.

Crowe MS, Wilson CD, Leishman E, Prather PL, Bradshaw HB, Banks ML, and Kinsey SG (2017) The monoacylglycerol lipase inhibitor KML29 with gabapentin synergistically produces analgesia in mice. $\mathrm{Br}$ J Pharmacol 174:4523-4539.

Deng L, Cornett BL, Mackie K, and Hohmann AG (2015a) CB1 knockout mice unveil sustained CB2-mediated antiallodynic effects of the mixed CB1/CB2 agonist CP55,940 in a mouse model of paclitaxel-induced neuropathic pain. Mol Pharmacol 88:64-74.

Deng L, Guindon J, Cornett BL, Makriyannis A, Mackie K, and Hohmann AG (2015b) Chronic cannabinoid receptor 2 activation reverses paclitaxel neuropathy without tolerance or cannabinoid receptor 1-dependent withdrawal. Biol Psychiatry 77: 475-487.

Dinh TP, Carpenter D, Leslie FM, Freund TF, Katona I, Sensi SL, Kathuria S, and Piomelli D (2002) Brain monoglyceride lipase participating in endocannabinoid inactivation. Proc Natl Acad Sci USA 99:10819-10824.

Dougherty PM, Cata JP, Cordella JV, Burton A, and Weng HR (2004) Taxol-induced sensory disturbance is characterized by preferential impairment of myelinated fiber function in cancer patients. Pain 109:132-142.

Gamage TF, Ignatowska-Jankowska BM, Muldoon PP, Cravatt BF, Damaj MI and Lichtman AH (2015) Differential effects of endocannabinoid catabolic inhibitors on morphine withdrawal in mice. Drug Alcohol Depend 146:7-16.

Ghersi D, Willson ML, Chan MM, Simes J, Donoghue E, and Wilcken N (2015 Taxane-containing regimens for metastatic breast cancer. Cochrane Database Syst Rev 10(6):CD003366.

Ghosh S, Wise LE, Chen Y, Gujjar R, Mahadevan A, Cravatt BF, and Lichtman AH (2013) The monoacylglycerol lipase inhibitor JZL184 suppresses inflammatory pain in the mouse carrageenan model. Life Sci 92:498-505.

Grim TW, Morales AJ, Thomas BF, Wiley JL, Endres GW, Negus SS, and Lichtman AH (2017) Apparent CB1 receptor rimonabant affinity estimates: combination with THC and synthetic cannabinoids in the mouse in vivo triad model. J Pharmacol Exp Ther 362:210-218.

Guindon J, Lai Y, Takacs SM, Bradshaw HB, and Hohmann AG (2013) Alterations in endocannabinoid tone following chemotherapy-induced peripheral neuropathy: effects of endocannabinoid deactivation inhibitors targeting fatty-acid amide hydrolase and monoacylglycerol lipase in comparison to reference analgesics following cisplatin treatment. Pharmacol Res 67:94-109.

Havelin J, Imbert I, Cormier J, Allen J, Porreca F, and King T (2016) Central sensitization and neuropathic features of ongoing pain in a rat model of advanced osteoarthritis. J Pain 17:374-382.

Hsu K-L, Tsuboi K, Adibekian A, Pugh H, Masuda K, and Cravatt BF (2012) DAGL $\beta$ inhibition perturbs a lipid network involved in macrophage inflammatory responses. Nat Chem Biol 8:999-1007.

Hudmon A, Choi JS, Tyrrell L, Black JA, Rush AM, Waxman SG, and Dib-Hajj SD (2008) Phosphorylation of sodium channel $\mathrm{Na}(\mathrm{v}) 1.8$ by p38 mitogen-activated protein kinase increases current density in dorsal root ganglion neurons. $\mathrm{J} \mathrm{Neu}$ rosci 28:3190-3201.

Huisman C, Ferreira CG, Bröker LE, Rodriguez JA, Smit EF, Postmus PE, Kruyt FA, and Giaccone G (2002) Paclitaxel triggers cell death primarily via caspaseindependent routes in the non-small cell lung cancer cell line NCI-H460. Clin Cancer Res 8:596-606.

Ignatowska-Jankowska B, Wilkerson JL, Mustafa M, Abdullah R, Niphakis M, Wiley JL, Cravatt BF, and Lichtman AH (2015) Selective monoacylglycerol lipase inhibitors: antinociceptive versus cannabimimetic effects in mice. J Pharmacol Exp Ther 353:424-432.

Johnson BE, Crawford J, Downey RJ, Ettinger DS, Fossella F, Grecula JC, Jahan T, Kalemkerian GP, Kessinger A, Koczywas M, et al.; National Comprehensive Cancer Network (NCCN) (2006) Small cell lung cancer clinical practice guidelines in oncology. J Natl Compr Canc Netw 4:602-622.

Jung H, Toth PT, White FA, and Miller RJ (2008) Monocyte chemoattractant protein1 functions as a neuromodulator in dorsal root ganglia neurons. $J$ Neurochem 104: $254-263$.

Kim JH, Dougherty PM, and Abdi S (2015) Basic science and clinical management of painful and non-painful chemotherapy-related neuropathy. Gynecol Oncol 136: $453-459$.

King T, Vera-Portocarrero L, Gutierrez T, Vanderah TW, Dussor G, Lai J, Fields HL, and Porreca F (2009) Unmasking the tonic-aversive state in neuropathic pain. Nat Neurosci 12:1364-1366.

Kinsey SG, O'Neal ST, Long JZ, Cravatt BF, and Lichtman AH (2011) Inhibition of endocannabinoid catabolic enzymes elicits anxiolytic-like effects in the marble burying assay. Pharmacol Biochem Behav 98:21-27.

Kinsey SG, Wise LE, Ramesh D, Abdullah R, Selley DE, Cravatt BF, and Lichtman $\mathrm{AH}$ (2013) Repeated low-dose administration of the monoacylglycerol lipase inhibitor JZL184 retains cannabinoid receptor type 1-mediated antinociceptive and gastroprotective effects. J Pharmacol Exp Ther 345:492-501. 
Kota D, Martin BR, Robinson SE, and Damaj MI (2007) Nicotine dependence and reward differ between adolescent and adult male mice. J Pharmacol Exp Ther 322 : $399-407$.

Krukowski K, Ma J, Golonzhka O, Laumet GO, Gutti T, van Duzer JH, Mazitschek R, Jarpe MB, Heijnen CJ, and Kavelaars A (2017) HDAC6 inhibition effectively reverses chemotherapy-induced peripheral neuropathy. Pain 158:1126-1137.

Li Y, Zhang H, Kosturakis AK, Cassidy RM, Zhang H, Kennamer-Chapman RM, Jawad AB, Colomand CM, Harrison DS, and Dougherty PM (2015) MAPK signaling downstream to TLR4 contributes to paclitaxel-induced peripheral neuropathy. Brain Behav Immun 49:255-266.

Li Y, Zhang H, Zhang H, Kosturakis AK, Jawad AB, and Dougherty PM (2014) Tolllike receptor 4 signaling contributes to paclitaxel-induced peripheral neuropathy. $J$ Pain 15:712-725.

Long JZ, Li W, Booker L, Burston JJ, Kinsey SG, Schlosburg JE, Pavón FJ, Serrano AM, Selley DE, Parsons LH, et al. (2009) Selective blockade of 2 -arachidonoylglycerol hydrolysis produces cannabinoid behavioral effects. Nat Chem Biol 5:37-44.

Makker PG, Duffy SS, Lees JG, Perera CJ, Tonkin RS, Butovsky O, Park SB, Goldstein D, and Moalem-Taylor G (2017) Characterisation of immune and neuroinflammatory changes associated with chemotherapy-induced peripheral neuropathy. PLoS One 12:e170814.

Marostica LL, Silva IT, Kratz JM, Persich L, Geller FC, Lang KL, Caro MSB, Durán FJ, Schenkel EP, and Simões CMO (2015) Synergistic antiproliferative effects of a new cucurbitacin B derivative and chemotherapy drugs on lung cancer cell line A549. Chem Res Toxicol 28:1949-1960.

Mechoulam R, Ben-Shabat S, Hanus L, Ligumsky M, Kaminski NE, Schatz AR, Gopher A, Almog S, Martin BR, Compton DR, et al. (1995) Identification of an endogenous 2-monoglyceride, present in canine gut, that binds to cannabinoid receptors. Biochem Pharmacol 50:83-90.

Mogil JS (2009) Animal models of pain: progress and challenges. Nat Rev Neurosci 10:283-294.

Navratilova E and Porreca F (2014) Reward and motivation in pain and pain relief. Nat Neurosci 17:1304-1312.

Niphakis MJ, Cognetta AB, III, Chang JW, Buczynski MW, Parsons LH, Byrne F, Burston JJ, Chapman V, and Cravatt BF (2013) Evaluation of NHS carbamates as a potent and selective class of endocannabinoid hydrolase inhibitors. ACS Chem Neurosci 4:1322-1332.

Nomura DK, Lombardi DP, Chang JW, Niessen S, Ward AM, Long JZ, Hoover HH, and Cravatt BF (2011a) Monoacylglycerol lipase exerts dual control over endocannabinoid and fatty acid pathways to support prostate cancer. Chem Biol 18:846-856.

Nomura DK, Long JZ, Niessen S, Hoover HS, Ng SW, and Cravatt BF (2010) Monoacylglycerol lipase regulates a fatty acid network that promotes cancer pathogenesis. Cell 140:49-61.

Nomura DK, Morrison BE, Blankman JL, Long JZ, Kinsey SG, Marcondes MC, Ward AM, Hahn YK, Lichtman AH, Conti B, et al. (2011b) Endocannabinoid hydrolysis generates brain prostaglandins that promote neuroinflammation. Science $\mathbf{3 3 4}$ 809-813.

Park CH, Shin TK, Lee HY, Kim SJ, and Lee WS (2011) Matrix metalloproteinase inhibitors attenuate neuroinflammation following focal cerebral ischemia in mice. Korean J Physiol Pharmacol 15:115-122.

Park HJ, Stokes JA, Pirie E, Skahen J, Shtaerman Y, and Yaksh TL (2013) Persistent hyperalgesia in the cisplatin-treated mouse as defined by threshold measures, the conditioned place preference paradigm, and changes in dorsal root ganglia activated transcription factor 3: the effects of gabapentin, ketorolac, and etanercept. Anesth Analg 116:224-231.

Pascual D, Goicoechea C, Suardíaz M, and Martín MI (2005) A cannabinoid agonist, WIN 55,212-2, reduces neuropathic nociception induced by paclitaxel in rats. Pain 118:23-34

Peters CM, Jimenez-Andrade JM, Kuskowski MA, Ghilardi JR, and Mantyh PW (2007) An evolving cellular pathology occurs in dorsal root ganglia, periphera nerve and spinal cord following intravenous administration of paclitaxel in the rat. Brain Res 1168:46-59.

Pevida M, Lastra A, Hidalgo A, Baamonde A, and Menéndez L (2013) Spinal CCL2 and microglial activation are involved in paclitaxel-evoked cold hyperalgesia. Brain Res Bull 95:21-27.

Rahn EJ, Zvonok AM, Thakur GA, Khanolkar AD, Makriyannis A, and Hohmann AG (2008) Selective activation of cannabinoid CB2 receptors suppresses neuropathic nociception induced by treatment with the chemotherapeutic agent paclitaxel in rats. J Pharmacol Exp Ther 327:584-591.

Ramesh D, Ross GR, Schlosburg JE, Owens RA, Abdullah RA, Kinsey SG, Long JZ Nomura DK, Sim-Selley LJ, Cravatt BF, et al. (2011) Blockade of endocannabinoid hydrolytic enzymes attenuates precipitated opioid withdrawal symptoms in mice. J Pharmacol Exp Ther 339:173-185.

Samudio-Ruiz SL, Allan AM, Valenzuela CF, Perrone-Bizzozero NI, and Caldwell KK (2009) Prenatal ethanol exposure persistently impairs NMDA receptor-dependent activation of extracellular signal-regulated kinase in the mouse dentate gyrus. J Neurochem 109:1311-1323.
Sanjakdar SS, Maldoon PP, Marks MJ, Brunzell DH, Maskos U, McIntosh JM, Bowers MS, and Damaj MI (2015) Differential roles of $\alpha 6 \beta 2 *$ and $\alpha 4 \beta 2 *$ neuronal nicotinic receptors in nicotine- and cocaine-conditioned reward in mice. Neuropsychopharmacology 40:350-360.

Schlosburg JE, Blankman JL, Long JZ, Nomura DK, Pan B, Kinsey SG, Nguyen PT, Ramesh D, Booker L, Burston JJ, et al. (2010) Chronic monoacylglycerol lipase blockade causes functional antagonism of the endocannabinoid system. Nat Neurosci 13:1113-1119.

Sciolino NR, Zhou W, and Hohmann AG (2011) Enhancement of endocannabinoid signaling with JZL184, an inhibitor of the 2-arachidonoylglycerol hydrolyzing enzyme monoacylglycerol lipase, produces anxiolytic effects under conditions of high environmental aversiveness in rats. Pharmacol Res 64:226-234.

Seretny M, Currie GL, Sena ES, Ramnarine S, Grant R, MacLeod MR, Colvin LA, and Fallon M (2014) Incidence, prevalence, and predictors of chemotherapyinduced peripheral neuropathy: a systematic review and meta-analysis. Pain 155: 2461-2470.

Shi C, Liu Y, Zhang W, Lei Y, Lu C, Sun R, Sun Y, Jiang M, Gu X, and Ma Z (2017) Intraoperative electroacupuncture relieves remifentanil-induced postoperative hyperalgesia via inhibiting spinal glial activation in rats. Mol Pain 13: 1744806917725636

Slivicki RA, Xu Z, Kulkarni PM, Pertwee RG, Mackie K, Thakur GA, and Hohmann AG (2017) Positive allosteric modulation of cannabinoid receptor type 1 suppresses pathological pain without producing tolerance or dependence. Biol Psychiatry 11 $1-12$.

Sugiura T, Kondo S, Sukagawa A, Nakane S, Shinoda A, Itoh K, Yamashita A, and Waku K (1995) 2-Arachidonoylglycerol: a possible endogenous cannabinoid receptor ligand in brain. Biochem Biophys Res Commun 215:89-97.

Tanabe Y, Hashimoto K, Shimizu C, Hirakawa A, Harano K, Yunokawa M, Yonemori K, Katsumata N, Tamura K, Ando M, et al. (2013) Paclitaxel-induced peripheral neuropathy in patients receiving adjuvant chemotherapy for breast cancer. Int $J$ Clin Oncol 18:132-138.

Toma W, Kyte SL, Bagdas D, Alkhlaif Y, Alsharari SD, Lichtman AH, Chen ZJ, Del Fabbro E, Bigbee JW, Gewirtz DA, et al. (2017) Effects of paclitaxel on the development of neuropathy and affective behaviors in the mouse. Neuropharmacology 117:305-315.

Uchida H, Nagai J, and Ueda H (2014) Lysophosphatidic acid and its receptors LPA1 and LPA3 mediate paclitaxel-induced neuropathic pain in mice. Mol Pain 10:71.

Wilkerson JL, Gentry KR, Dengler EC, Wallace JA, Kerwin AA, Kuhn MN, Zvonok AM, Thakur GA, Makriyannis A, and Milligan ED (2012) Immunofluorescent spectral analysis reveals the intrathecal cannabinoid agonist, AM1241, produces spinal anti-inflammatory cytokine responses in neuropathic rats exhibiting relief from allodynia. Brain Behav 2:155-177.

Wilkerson JL, Ghosh S, Bagdas D, Mason BL, Crowe MS, Hsu KL, Wise LE, Kinsey SG, Damaj MI, Cravatt BF, et al. (2016a) Diacylglycerol lipase $\beta$ inhibition reverses nociceptive behaviour in mouse models of inflammatory and neuropathic pain. Br J Pharmacol 173:1678-1692.

Wilkerson JL, Niphakis MJ, Grim TW, Mustafa MA, Abdullah RA, Poklis JL, Dewey WL, Akbarali H, Banks ML, Wise LE, et al. (2016b) The selective monoacylglycerol lipase inhibitor MJN110 produces opioid sparing effects in a mouse neuropathic pain model. J Pharmacol Exp Ther 357:145-156.

Zhang H, Boyette-Davis JA, Kosturakis AK, Li Y, Yoon SY, Walters ET, and Dougherty PM (2013) Induction of monocyte chemoattractant protein-1 (MCP-1) and its receptor CCR2 in primary sensory neurons contributes to paclitaxel-induced peripheral neuropathy. J Pain 14:1031-1044

Zhang H, Li Y, de Carvalho-Barbosa M, Kavelaars A, Heijnen CJ, Albrecht PJ, and Dougherty PM (2016) Dorsal root ganglion infiltration by macrophages contributes to paclitaxel chemotherapy-induced peripheral neuropathy. J Pain 17: $775-786$.

Zhang H, Yoon SY, Zhang H, and Dougherty PM (2012) Evidence that spinal astrocytes but not microglia contribute to the pathogenesis of paclitaxel-induced painful neuropathy. J Pain 13:293-303.

Zhong P, Wang W, Pan B, Liu X, Zhang Z, Long JZ, Zhang H-T, Cravatt BF, and Liu Q-S (2014) Monoacylglycerol lipase inhibition blocks chronic stress-induced depressive-like behaviors via activation of mTOR signaling. Neuropsychopharmacology 39:1763-1776.

Zimmer A, Zimmer AM, Hohmann AG, Herkenham M, and Bonner TI (1999) Increased mortality, hypoactivity, and hypoalgesia in cannabinoid CB1 receptor knockout mice. Proc Natl Acad Sci USA 96:5780-5785.

Zoja C, Liu X-H, Donadelli R, Abbate M, Testa D, Corna D, Taraboletti G, Vecchi A Dong QG, Rollins BJ, et al. (1997) Renal expression of monocyte chemoattractant protein-1 in lupus autoimmune mice. J Am Soc Nephrol 8:720-729.

Address correspondence to: Aron H. Lichtman, Department of Pharmacology and Toxicology, Virginia Commonwealth University, P.O. Box 980613, Richmond, VA 23298-0613. E-mail: aron.lichtman@vcuhealth.org 